This is the final peer-reviewed accepted manuscript of:

Luca Valgimigli, Andrea Baschieri and Riccardo Amorati

Antioxidant activity of nanomaterials

J. Mater. Chem. B, 2018, 6, 2036

The final published version is available online at: DOI: 10.1039/c8tb00107c

Rights / License:

The terms and conditions for the reuse of this version of the manuscript are specified in the publishing policy. For all terms of use and more information see the publisher's website.

This item was downloaded from IRIS Università di Bologna (https://cris.unibo.it/)

When citing, please refer to the published version. 


\title{
Antioxidant activity of nanomaterials
}

\author{
Luca Valgimigli, Andrea Baschieri, Riccardo Amorati*
}

Department of Chemistry “G. Ciamician”, University of Bologna, Via S. Giacomo 11, 40126

Bologna, Italy. E-mail: Riccardo.amorati@unibo.it

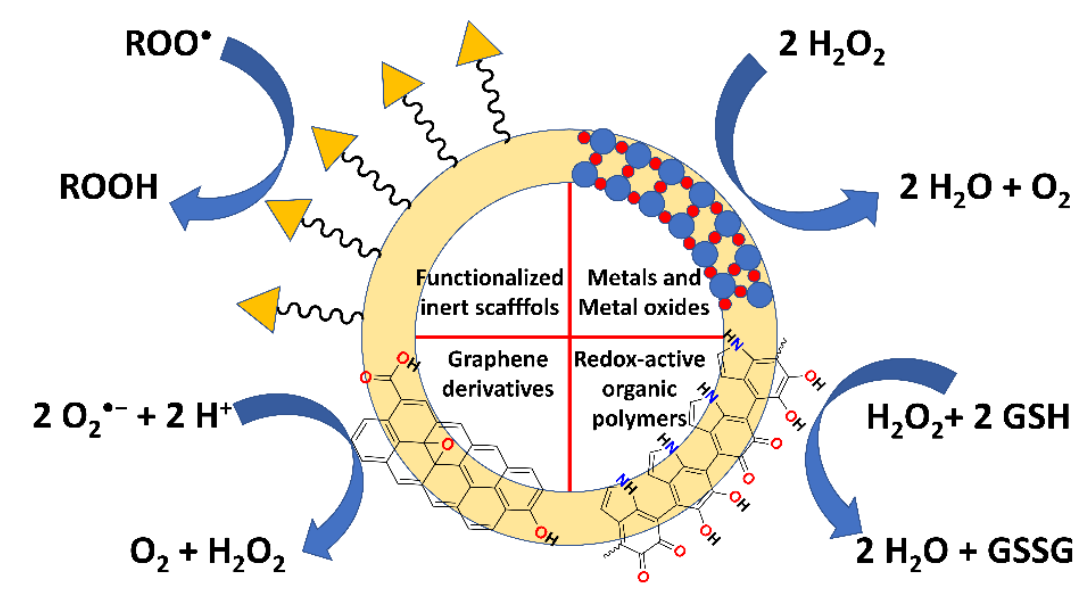

\begin{abstract}
Nanomaterials represent one of the most promising frontiers in the research for improved antioxidants. Some nanomaterials, including organic (i.e. melanin, lignin) metal oxides (i.e. cerium oxide) or metal (i.e gold, platinum) based nanoparticles, exhibit intrinsic redox activity that is often associated with radical trapping and/or with superoxide dismutase-like and catalase-like activities. Redox inactive nanomaterials can be transformed into antioxidants by grafting low molecular weight antioxidants on them. Herein, we propose a classification of nanoantioxidants based on their mechanism of action, and we review the chemical methods used to measure antioxidant activity by providing a rationale of the chemistry behind them.
\end{abstract}




\section{1) INTRODUCTION}

Oxidative degradation of organic materials, including biological molecules such as lipids and proteins, as well as foods and cosmetics, is due to a radical-chain mechanism in which alkyl radicals are converted by atmospheric $\mathrm{O}_{2}$ into peroxyl radicals $(\mathrm{ROO} \bullet$ ) that propagate the oxidative chain. This reaction is known as autoxidation, because it occurs under mild conditions without an apparent cause; or as peroxidation, because hydroperoxides (alkyl hydroperoxides and $\mathrm{H}_{2} \mathrm{O}_{2}$ ) are the main firstly formed products. ${ }^{1}$ Hydroperoxides are themselves unstable and can be cleaved homolytically, forming hydroxyl $(\mathrm{HO} \bullet)$ or alkoxyl $(\mathrm{RO} \bullet$ ) radicals, which are extremely reactive and can attack even relatively stable molecules such as DNA bases. ${ }^{2}$ Alkyl hydroperoxide cleavage also causes the formation of reactive carbonyl species (such as 4-hydroxynonenal) that amplify the oxidative damage. ${ }^{3}$ Oxidative stress, defined as the imbalance between the formation of reactive oxygen species (ROS) and the cell's ability to provoke an effective antioxidant response, causes the accumulation of irreversible damages to proteins, lipids, and to DNA, leading to mutations and cell death. ${ }^{4}$

Like any other radical chain reaction, autoxidation is composed of three steps: initiation, propagation and termination, as shown in Scheme $1 .{ }^{1}$ Autoxidation can be initiated by several processes yielding $\mathrm{X} \bullet$ radicals, such as light- or heat-induced homolytic cleavage of weak bonds, or electron transfers involving transition metals and hydroperoxides (Scheme 1). Depending on their way of formation, $\mathrm{X} \bullet$ radicals can be represented by hydroxyl $(\mathrm{HO} \bullet)$, alkyl $(\mathrm{R} \bullet$, alkoxyl $(\mathrm{RO} \bullet)$, or hydroperoxyl (HOO•) radicals. Initiating radicals react with the substrate $\mathrm{RH}$, most commonly by $\mathrm{H}$-atom abstraction, to yield alkyl radicals $\mathrm{R} \bullet$, which react at a diffusion controlled rate with oxygen to form peroxyl radicals (ROO•). Peroxyl radicals ROO• attack the substrate to give hydroperoxides (ROOH) and new R $^{\circ}$ radicals, establishing a chain-reaction, that proceeds for many cycles before two radicals incidentally quench each other in the termination step (see Scheme 1). In biological systems, oxidizable molecules are represented mainly by lipids (e.g. triglycerides and cholesterol) ${ }^{5}$ proteins, ${ }^{6}$ and carbohydrates. ${ }^{7}$ 


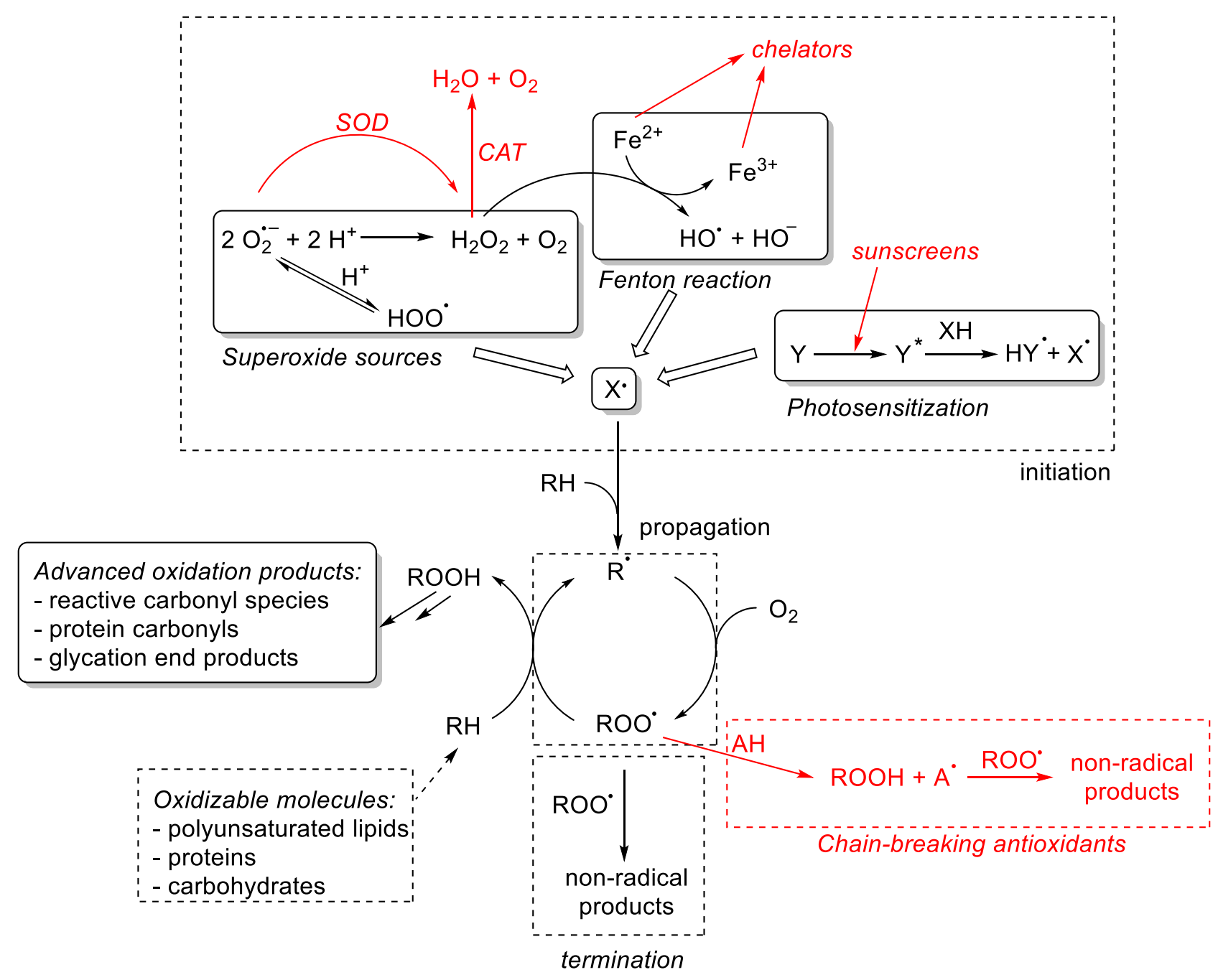

Scheme 1. Radical-chain mechanism of the autoxidation of a substrate ( $\mathrm{RH})$, to form an alkyl hydroperoxide $(\mathrm{ROOH})$, reporting the main initiation mechanisms. The possible ways for antioxidant action are showed in red. $\mathrm{X} \bullet=$ initiating radical; $\mathrm{SOD}=$ superoxide dismutase; $\mathrm{CAT}=$ catalase; $\mathrm{AH}$ $=$ chain-breaking antioxidant .

\subsection{Classification of antioxidant action}

An antioxidant is a substance (molecule or nanomaterial) that, when added to oxidizable molecules in small amounts, protects them by slowing down or inhibiting their autoxidation. ${ }^{1}$

Preventive antioxidants. The action of preventive antioxidants is to reduce the initiation rate. ${ }^{8}$ This is an heterogeneous class of compounds that comprises sunscreens, ${ }^{9}$ metal chelators, ${ }^{10}$ hydroperoxide-decomposing agents ${ }^{11}$ - both small molecules and enzymes like glutathione 
peroxidase (GPX) - and superoxide dismutase (SOD) or their mimics. ${ }^{12}$ One of the main sources of initiation is the Fenton reaction occurring between the reduced state of transition metal ions (e.g. $\mathrm{Fe}^{2+}$ ) and hydrogen peroxide $\left(\mathrm{H}_{2} \mathrm{O}_{2}\right)$ or organic hydroperoxides $(\mathrm{ROOH})$. Molecules that react with hydroperoxides without generating free radicals are effective preventive antioxidants, such as the enzymes catalase (CAT) and glutathione peroxidase (GPX) and small-molecules containing chalcogen atoms (mainly $\mathrm{Se}$ and $\mathrm{Te}$ ). ${ }^{13}$ Despite the radical nature of superoxide, SOD-like antioxidants can be classified as preventive. Indeed, superoxide $\left(\mathrm{HOO} \bullet / \mathrm{O}_{2}{ }^{--}\right)$is an unconventional oxygen-centered radical. At physiological $\mathrm{pH}$, superoxide is mostly in its deprotonated form $\left(\mathrm{p} K_{\mathrm{a}(\mathrm{HOO} \cdot)}=4.7\right)$ which has reducing rather than oxidizing ability, and only the small amount of neutral $\mathrm{HOO}$ - present at the equilibrium is able to directly initiate the autoxidation (Scheme 1). ${ }^{14}$ Differently to classical chain-breaking antioxidants, the most active superoxide quenchers usually act in a catalytic fashion. They are both reduced and oxidized by superoxide with a ping-pong mechanism, similarly to the active site of the enzyme superoxide dismutase (SOD). The maximum SOD-like activity is reached when both the oxidation and reduction reactions are optimized and sufficiently rapid. ${ }^{15}$

\section{Chain-breaking antioxidants.}

These antioxidants, also called radical-trapping antioxidants, slow down (or block) the autoxidation by competing with the propagation reactions; i.e. peroxyl radicals react with them more rapidly than with the substrate. Typically, the reaction between the antioxidant (AH) and a peroxyl radical (ROO•) is a formal $\mathrm{H}$ atom transfer, to yield a hydroperoxide and the radical of the antioxidant $(\mathrm{A} \bullet$, which traps a second ROO forming non-radical end products. ${ }^{1}$ With a few exceptions, in the absence of regenerating systems, chain-breaking antioxidants are consumed during the reaction, hence they act in a stoichiometric fashion. Here, it should be noted that the only important reaction of chain-breaking antioxidants is that with peroxyl radicals, while the reactions with the other radical species, formed during the autoxidation, are less relevant. In the case of $\mathrm{R} \bullet$, its reaction with $\mathrm{O}_{2}$ is so fast that the possibility that it is trapped by an antioxidant is indeed modest. In the case of $\mathrm{HO} \bullet$ and $\mathrm{RO} \bullet$ initiating 
radicals, they are characterized by a very high reactivity toward any organic molecule, so that the antioxidant, which by definition is present in small amounts, cannot compete with these reactions. ${ }^{8}$ The rules for a molecule $(\mathrm{AH})$ to be a chain-breaking antioxidant are: i) to have high reactivity toward ROO•; ii) to yield a radical $\mathrm{A} \bullet$ that does not propagate the autoxidation; and iii) to be stable under air. Phenols are perhaps the best examples of this class of antioxidants: they can rapidly trap 2 peroxyl radicals per molecule, therefore they have a stoichiometric factor $(n)$ equal to 2 . Polyphenols, having more phenolic units, can have larger stoichiometric factors. ${ }^{8}$ Well known examples of natural chainbreaking antioxidants are tocopherols (vitamin E), flavonoids, stilbenes (e.g. resveratrol) and ascorbate (vitamin C), while synthetic alternatives are BHA, BHT, aromatic amines and nitroxides.

\subsection{Nanoantioxidants}

Nanontioxidants can be defined as nanomaterials capable of slowing the overall rate of autoxidation by trapping the chain-carrying radicals, or by decreasing the initiation events. Dietary antioxidants, such as vitamin E, $\beta$-carotene, selenium, glutathione and polyphenols have drawn attention as pharmacological means to reduce ROS levels and to counteract diseases linked to oxidative stress. ${ }^{16}$ However, clinical trials designed to provide evidence on the benefit of supplementation of $\alpha$ tocopherol, selenium or $\beta$-carotene for reducing the risk of cancer typically showed no protection or even an increased death risk. ${ }^{4}$ Among the possible reasons for such unexpected results, one of the most important is the inability of most antioxidants to reach biologically relevant targets. ${ }^{4}$ In this context, nanoantioxidants present a unique opportunity because they can be designed so to have prolonged stability compared to small molecules, to avoid rapid metabolic clearance, and to target specific sites. In general, nanomaterials may behave as passive delivery carriers of small-molecular antioxidants, or may possess inherent antioxidant properties. ${ }^{4}$ To guide the development of novel nanoantioxidants, in-vitro chemical tests aimed at measuring their antioxidant activity are of fundamental importance. In this review, we propose a classification of nanoantioxidants based on 
their mechanism of action, and we aim at helping the reader to disentangle among the plethora of methods used to measure antioxidant activity by providing a rationale of the chemistry behind them (Figure 1). We will cover the field of intrinsically antioxidant materials and of inert scaffolds with antioxidants covalently bound on the surface, as they pose new challenges for the determination of antioxidants properties. On the other hand, the important and wide field of nanomaterials able to deliver and release antioxidants (i.e. nanoencapsulation, ${ }^{17}$ inclusion in biodegradable ${ }^{18,19}$ or in solid lipid nanoparticles,${ }^{20}$ loading in nanotubes ${ }^{21}$ or mesoporous materials ${ }^{22}$ etc...) is outside the scope of this review, as their antioxidant capacity is essentially due to the release in solution of small-molecule antioxidants, whose activity is usually already known.

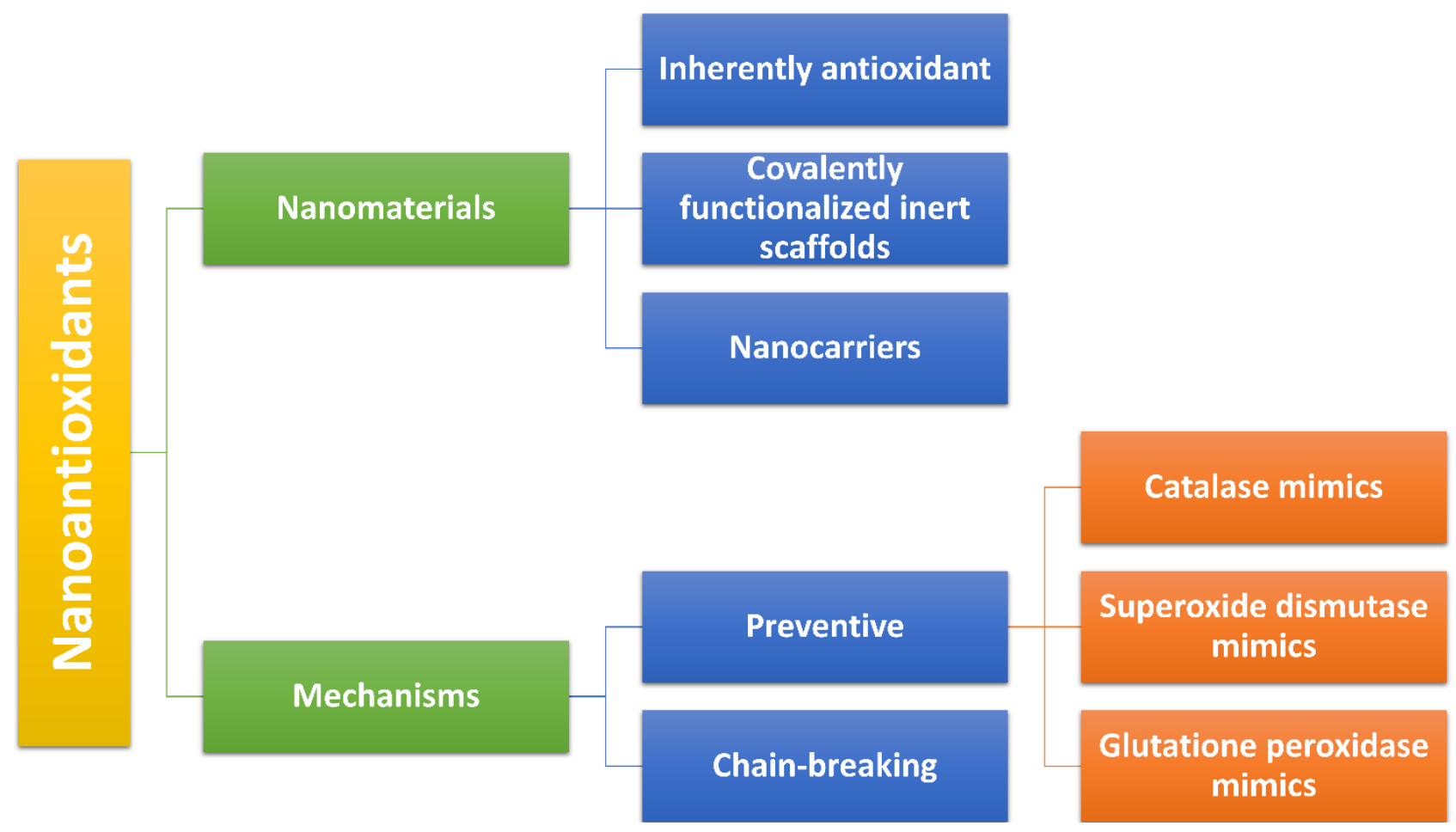

Figure 1. Classification of nanoantioxidants based on their structural properties and on their mechanism of action.

\section{2) NANOMATERIALS WITH ANTIOXIDANT ACTIVITY}

\subsection{Inherently antioxidant nanomaterials}


Several types of nanomaterials possess intrinsic antioxidant properties that do not depend on their functionalization with antioxidants, but on the surface properties of the material itself. Most of such materials are inorganic metal nanoparticles (NPs); however, also all-organic NPs are becoming increasingly important, and some examples are reported below.

CAT-mimics. Catalase (CAT) mimics act by decomposing $\mathrm{H}_{2} \mathrm{O}_{2}$ to $\mathrm{H}_{2} \mathrm{O}$ and $\mathrm{O}_{2}$, as shown by equation 1 .

$2 \mathrm{H}_{2} \mathrm{O}_{2} \rightarrow 2 \mathrm{H}_{2} \mathrm{O}+\mathrm{O}_{2}$

In the literature, there are several examples of metal (gold, silver, platinum and palladium $)^{23,24,25,26}$ and metal oxide $27,28,29,30,31,32,33$ NPs displaying catalase-mimic behavior (see Table 1). However, this activity occurs only at neutral or basic $\mathrm{pH}$ values, whereas at acidic $\mathrm{pH}$ values a prooxidant effect, similar to that of peroxidase enzymes, is observed. The prooxidant behavior is due to the release of $\mathrm{HO} \cdot$ radicals through the occurrence of Fenton reaction on the surface of the nanoparticle (equation 2)..$^{34}$

$\mathrm{H}_{2} \mathrm{O}_{2}+\mathrm{e}^{-} \rightarrow \mathrm{HO} \bullet+\mathrm{HO}^{-} \quad$ (Eq. 2)

This reaction is important for nanomaterials having peroxidase activity, which are useful for colorimetric sensing of glucose or DNA. ${ }^{35}$ This double-faced behavior limits the usefulness of such nanoantioxidants; at the same time, it provides an interesting way to develop $\mathrm{pH}$-responsive redox modulators of the oxidative stress inside cells. ${ }^{36}$ Although mechanisms underlying catalase activity are not fully clarified, ${ }^{37,38}$ in the case of cerium oxide nanoparticles, relatively stable surface peroxo/hydroperoxo species are involved. ${ }^{39}$ The oxidation state of a given nanomaterial can influence its CAT-like behavior. Cerium nanoparticles with high surface $\mathrm{Ce}^{4+} / \mathrm{Ce}^{3+}$ ratios function as efficient antioxidant CAT-mimetics. ${ }^{27}$. In the case of $\mathrm{Mn}_{3} \mathrm{O}_{4}$ NPs having flower-like morphology ("nanoflowers"), the material having higher $\mathrm{Mn}^{3+} / \mathrm{Mn}^{2+}$ ratio, obtained by oxidation with $\mathrm{NaIO}_{4}$, exhibited enhanced CAT activity as compared to material having a lower $\mathrm{Mn}^{3+} / \mathrm{Mn}^{2+}$ ratio. ${ }^{30}$ The CAT-like activity of three different $\mathrm{Co}_{3} \mathrm{O}_{4}$ nanomaterials decreased in the order nanoplates > nanorods > nanocubes, being inversely proportional to their redox potentials. This result was 
explained by considering that the cleavage of the $\mathrm{O}-\mathrm{O}$ bond occurring during the reduction of $\mathrm{H}_{2} \mathrm{O}_{2}$ by the nanomaterial (see Equation 2) is the rate-determining step in the CAT catalytic cycles. ${ }^{40}$ Environmental pH controls the switch between Fenton chemistry (low pH) and catalase activity (high $\mathrm{pH}$ ). This interesting behaviour could be at least in part caused by the $\mathrm{pH}$ dependence of the reaction between $\mathrm{HO}$ and $\mathrm{HOOH}$ (equation 3), which is expected to be favored by the partial deprotonation of $\mathrm{H}_{2} \mathrm{O}_{2}\left(\mathrm{pK}_{\mathrm{a}}=11.6\right){ }^{34}$

$\mathrm{H}_{2} \mathrm{O}_{2}+\mathrm{HO} \cdot \rightarrow \mathrm{O}_{2}^{\cdot-}+\mathrm{H}_{2} \mathrm{O}+\mathrm{H}^{+}$

On the basis of theoretical calculation, it has been proposed that the $\mathrm{pH}$ switch in the case of gold nanorods, core-shell gold-platinum and gold-palladium nanorods, is due to the absorption of either $\mathrm{H}^{+}$or $\mathrm{HO}^{-}$on the metal surface. ${ }^{23}$ The calculated adsorption energies between $\mathrm{H}_{2} \mathrm{O}_{2}$ and metals has been also proposed as convenient descriptors to estimate the relative enzymatic activities of the metals with similar surface structures. ${ }^{23}$

Table 1. Intrinsically antioxidant nanoparticles: mechanisms of action and chemical assays used to evaluate their activity.

\begin{tabular}{|c|c|c|c|}
\hline Nanoantioxidant & Action & Assay & Ref. \\
\hline $\begin{array}{l}\text { Polyvinylpyrrolidone } \\
\text { coated Au NPs }\end{array}$ & Catalase mimic $(\mathrm{pH}>7)$ & $\begin{array}{l}\mathrm{H}_{2} \mathrm{O}_{2} \text { decrease (spectrophotometric), } \mathrm{O}_{2} \text { evolution } \\
(\mathrm{EPR})\end{array}$ & 24 \\
\hline Cerium oxide NPs & Catalase mimic $(\mathrm{pH}>7)$ & $\begin{array}{l}\mathrm{H}_{2} \mathrm{O}_{2} \text { disappearance (spectrophotometric), } \mathrm{O}_{2} \\
\text { generation from } \mathrm{H}_{2} \mathrm{O}_{2} \text { (Clark electrode) }\end{array}$ & 29 \\
\hline $\mathrm{Co}_{3} \mathrm{O}_{4} \mathrm{NPs}$ & Catalase mimic $(\mathrm{pH}>7)$ & $\mathrm{O}_{2}$ generation from $\mathrm{H}_{2} \mathrm{O}_{2}$ (Clark electrode $)$ & $\begin{array}{l}28 \\
33\end{array}$ \\
\hline $\begin{array}{l}\text { Au nanorods; core-shell } \\
\text { Au@Pt nanorods; core- } \\
\text { shell Au@Pd nanorods }\end{array}$ & Catalase mimic $(\mathrm{pH}>7)$ & $\begin{array}{l}\mathrm{H}_{2} \mathrm{O}_{2} \text { decrease (spectrophotometric), } \mathrm{O}_{2} \text { evolution } \\
\text { (Clark electrode) }\end{array}$ & 23 \\
\hline Apoferritin coated Pt NPs & Catalase mimic $(\mathrm{pH}>7)$ & $\begin{array}{l}\mathrm{H}_{2} \mathrm{O}_{2} \text { consumption, formation of bubbles attributed to } \\
\mathrm{O}_{2}\end{array}$ & 25 \\
\hline Pt nanopowder & Catalase mimic $(\mathrm{pH}>7)$ & $\mathrm{O}_{2}$ detection by EPR line broadening & 26 \\
\hline $\mathrm{Mn}_{3} \mathrm{O}_{4}$ "nanoflowers" & Catalase mimic $(\mathrm{pH}>7)$ & $\mathrm{H}_{2} \mathrm{O}_{2}$ decrease (spectrophotometric) & 30 \\
\hline $\begin{array}{l}\text { Dimercaptosuccinic acid } \\
\text { coated } \mathrm{Fe}_{3} \mathrm{O}_{4} \mathrm{NPs}\end{array}$ & Catalase mimic $(\mathrm{pH}>7)$ & $\mathrm{O}_{2}$ evolution (Clark electrode) & 31 \\
\hline
\end{tabular}




\begin{tabular}{|c|c|c|c|}
\hline Eumelanin-silica NPs & Catalase mimic & $\mathrm{H}_{2} \mathrm{O}_{2}$ decrease (Ferrous xylenol orange assay) & 32 \\
\hline $\mathrm{V}_{2} \mathrm{O}_{5}$ nanowires & GPX mimic & $\begin{array}{l}\text { Glutathione reductase coupled assay } \\
\text { (spectrophotometric), change in absorbance of } \\
\text { coenzyme NADPH at } 340 \mathrm{~nm}\end{array}$ & 41 \\
\hline $\begin{array}{l}\text { Graphene oxide supported } \\
\text { selenium NPs }\end{array}$ & GPX mimic & $\begin{array}{l}\text { Glutathione reductase coupled assay } \\
\text { (spectrophotometric) }\end{array}$ & 43 \\
\hline $\mathrm{Mn}_{3} \mathrm{O}_{4}$ "nanoflowers" & GPX mimic & $\begin{array}{l}\text { Glutathione reductase coupled assay } \\
\text { (spectrophotometric) }\end{array}$ & 30 \\
\hline $\begin{array}{l}\text { Polyacrylic acid (PAA)- } \\
\text { protected Pt NPs }\end{array}$ & Chain-breaking, & $\begin{array}{l}\text { Inhibit linoleic acid peroxidation }\left(\mathrm{O}_{2} \text { consumption by }\right. \\
\text { Clark electrode), DPPH (spectrophotometric), } \\
\text { AAPH-derived radicals scavenging (EPR detection) }\end{array}$ & 56 \\
\hline $\begin{array}{l}\text { Oleic acid coated cerium } \\
\text { oxide NPs }\end{array}$ & Chain-breaking & AAPH-derived radicals scavenging (ORAC assay) & 57 \\
\hline $\mathrm{ZrO}_{2} \mathrm{NPs}$ & Chain-breaking & DPPH (spectrophotometric) & 58 \\
\hline PEG coated melanin NPs & Chain-breaking & DPPH (spectrophotometric and EPR) & 59 \\
\hline PEG coated melanin NPs & SOD mimic & $\begin{array}{l}\text { EPR study of the reaction with } \mathrm{KO}_{2} \text { with 5- } \\
\text { diethoxyphosphoryl-5-methyl-1-pyrroline } \mathrm{N} \text { oxide } \\
\text { (DEPMPO), } \mathrm{O}_{2} \text { evolution (Clark electrode) }\end{array}$ & 54 \\
\hline $\begin{array}{l}\text { Polyvinylpyrrolidone } \\
\text { coated Au NPs }\end{array}$ & SOD mimic & $\begin{array}{l}\text { Xanthine/xanthine oxidase and a spin-trap with EPR } \\
\text { detection }\end{array}$ & 24 \\
\hline $\begin{array}{l}\text { Glycine coated } \mathrm{Cu}(\mathrm{OH})_{2} \\
\text { NPs }\end{array}$ & SOD mimic & $\begin{array}{l}\text { Xanthine/xanthine oxidase and iodonitrotetrazolium } \\
\text { chloride (spectrophotometric) }\end{array}$ & 48 \\
\hline PEG coated MnO NPs & SOD mimic & $\begin{array}{l}\text { Xanthine/xanthine oxidase and cytochrome C } \\
\text { (spectrophotometric) }\end{array}$ & 49 \\
\hline $\begin{array}{l}\text { PEG coated carbon } \\
\text { nanoclusters }\end{array}$ & SOD mimic & EPR study of the reaction with $\mathrm{KO}_{2}$ & 50 \\
\hline Pd nanocrystals & SOD mimic & $\begin{array}{l}\text { Xanthine/xanthine oxidase and a spin-trap with EPR } \\
\text { detection }\end{array}$ & 47 \\
\hline Pt nanopowder & SOD mimic & $\begin{array}{l}\text { Xanthine/xanthine oxidase and a spin-trap with EPR } \\
\text { detection }\end{array}$ & 26 \\
\hline $\mathrm{Mn}_{3} \mathrm{O}_{4}$ "nanoflowers" & SOD mimic & $\begin{array}{l}\text { Xanthine/xanthine oxidase and iodonitrotetrazolium } \\
\text { chloride (spectrophotometric) }\end{array}$ & 30 \\
\hline $\begin{array}{l}\text { dimercapto succinic acid } \\
\text { coated } \mathrm{Co}_{3} \mathrm{O}_{4} \text { NPs }\end{array}$ & SOD mimic & $\begin{array}{l}\text { Xanthine/xanthine oxidase and a spin-trap with EPR } \\
\text { detection }\end{array}$ & 33 \\
\hline $\begin{array}{l}\text { Multiwalled carbon } \\
\text { nanotubes }\end{array}$ & SOD mimic & $\begin{array}{l}\text { Xanthine/xanthine oxidase and cytochrome c } \\
\text { (spectrophotometric) }\end{array}$ & 52 \\
\hline Functionalized fullerene & SOD mimic & Reaction with $\mathrm{KO}_{2}$ (spectrophotometric) & 52 \\
\hline Tris-malonyl-C60 & SOD mimic & $\begin{array}{l}\text { Xanthine/xanthine oxidase and cytochrome c } \\
\text { (spectrophotometric) }\end{array}$ & 53 \\
\hline
\end{tabular}


GPX mimics. Differently from catalase activity that is common for many metal and metal oxide materials, glutathione peroxidase (GPX) activity has been discovered only in the case of vanadium ${ }^{41}$ and manganese ${ }^{30}$ oxides (see Table 1). $\mathrm{V}_{2} \mathrm{O}_{5}$ nanowires are able to mediate the reduction of $\mathrm{H}_{2} \mathrm{O}_{2}$ to $\mathrm{H}_{2} \mathrm{O}$ at the expenses of glutathione (GSH), under physiological conditions, thanks to the unique ability of $\mathrm{V}_{2} \mathrm{O}_{5}$ to form polar peroxido species instead of $\mathrm{HO} \cdot$ radicals (equation 4$){ }^{42}$

$2 \mathrm{GSH}+\mathrm{H}_{2} \mathrm{O}_{2} \rightarrow \mathrm{GS}-\mathrm{SG}+2 \mathrm{H}_{2} \mathrm{O}$

GPX-like activity is instead common for compounds containing heavy chalcogen atoms, in particular selenium and tellurium. In fact, selenium nanoparticles supported on graphene oxide showed good GPX-like activity, thanks to the large surface area and the fast reactivity of these nanocomposites. ${ }^{43}$ SOD mimics. Antioxidants that trap superoxide radical need to be considered separately because, although the superoxide belongs to the family of peroxyl radicals, its peculiar chemistry distinguishes it from alkylperoxyl radicals. The conjugated acid of superoxide (HOO•) has a $\mathrm{p} K_{\mathrm{a}}$ value of 4.5 , therefore at physiologic $\mathrm{pH}$ the main form of superoxide is $\mathrm{O}_{2}{ }^{-4} \cdot{ }^{44}$ When protonated (i.e. neutral, $\mathrm{HOO} \bullet$ ), superoxide has a two-faced behavior, as it can both abstract an $\mathrm{H}$ atom to form $\mathrm{HOOH}$, and it can donate the $\mathrm{H}$ atom to form $\mathrm{O}_{2} \cdot{ }^{44} \mathrm{On}$ the other hand, deprotonated $\mathrm{O}_{2}{ }^{--}$is mainly a reducing species. ${ }^{45}$ Self-decay of superoxide is due to the reaction between the protonated and the deprotonated species, as illustrated by equation $5\left(k_{\mathrm{H} 2 \mathrm{O}}=8.9 \times 10^{7} \mathrm{M}^{-1} \mathrm{~s}^{-1}\right)$, while, at low $\mathrm{pH}$ and in organic solvents, the reaction between two protonated species becomes important, (equation $6, k_{\mathrm{H} 2 \mathrm{O}}=7.6 \times 10^{5} \mathrm{M}^{-1} \mathrm{~s}^{-}$ $\left.{ }^{1}\right)$. Instead, the reaction of two deprotonated radicals does not occur. ${ }^{46}$

$\mathrm{O}_{2}^{\cdot-}+\mathrm{HOO} \bullet+\mathrm{H}^{+} \rightarrow \mathrm{O}_{2}+\mathrm{H}_{2} \mathrm{O}_{2}$

$\mathrm{HOO} \bullet+\mathrm{HOO} \bullet \rightarrow \mathrm{O}_{2}+\mathrm{H}_{2} \mathrm{O}_{2}$

The self-decay of superoxide is, therefore, strongly $\mathrm{pH}$-dependent, having a maximum rate at $\mathrm{pH}=$ 4.5, and becoming slower on increasing the $\mathrm{pH}$. At $\mathrm{pH}=7.4$, this reaction has an apparent rate constant of $2 \times 10^{5} \mathrm{M}^{-1} \mathrm{~s}^{-1}$, making self-decay inefficient. This is conceivably the reason why Nature 
has developed the enzyme superoxide dismutase: to accelerate the process and decrease superoxide concentration into physiologic limits. ${ }^{12}$ In case of superoxide overproduction by cells, the small amount of $\mathrm{HOO} \cdot$ present at $\mathrm{pH}=7.4$ is able to initiate lipid peroxidation and cause radical damage to biomolecules. From a mechanistic point of view, quenching $\mathrm{HOO} \bullet / \mathrm{O}_{2}{ }^{--}$is simpler than quenching ROO• radicals, because the electron needed for the reduction of $\mathrm{O}_{2}{ }^{--} / \mathrm{HOO} \bullet$ to $\mathrm{H}_{2} \mathrm{O}_{2}$ can be provided by the oxidation of superoxide to oxygen $\left(\mathrm{O}_{2}{ }^{\cdot-} \rightarrow \mathrm{O}_{2}+\mathrm{e}^{-}\right)$, while protons are taken from solvent, as shown in Scheme 2. To achieve high SOD-like activity both the reduction and oxidation reactions must be very fast, since the slowest reaction limits the overall catalytic efficiency $\left(k_{\mathrm{cat}}\right)$, as shown in the equation 7 , where $k_{1}$ and $k_{2}$ are the reductive and the oxidative reactions, respectively (see Scheme $2) .{ }^{15}$

$k_{\text {cat }}=2 k_{1} k_{2} /\left(k_{1}+k_{2}\right)$

As a matter of facts, SOD-like activity has been demonstrated for nanomaterials having very different compositions: noble metals ${ }^{24,26,47}$ (gold, platinum, palladium), metal oxides ${ }^{30,33,49}$ (cerium, cobalt, manganese oxides), carbon clusters, ${ }^{50}$ carbon nanotubes,${ }^{51}$ fullerenes,${ }^{52,53}$ melanin ${ }^{54}$ (see also Table 1). Interestingly, SOD-like and GPX-like activities were achieved at the same time in a "multi nanozyme" based on $\mathrm{MnO}_{2}$ nanoparticles deposited on $\mathrm{V}_{2} \mathrm{O}_{5}$ nanowires through polydopamine. ${ }^{55}$ 


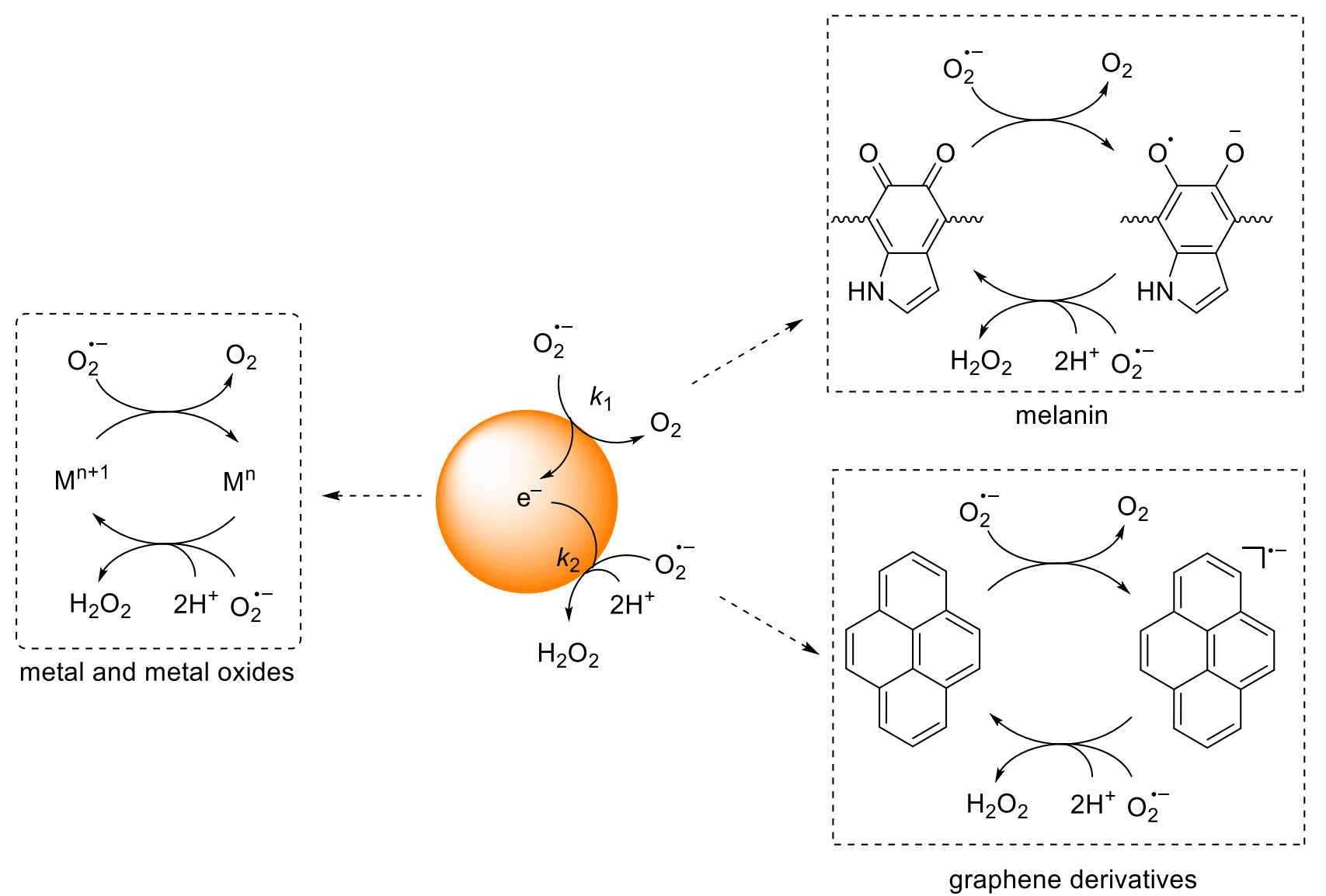

Scheme 2. SOD-like activity of nanomaterials.

Chain-breaking. As previously noted, the chain-breaking antioxidant action requires instead that a given nanomaterial is able to quench alkylperoxyl radicals, by transforming them into hydroperoxides. ${ }^{56,57,58,59}$ The quenching of alkylperoxyl radicals (ROO•, where $\mathrm{R}$ is an alkyl, e.g. from lipids) requires an electron and a proton, ${ }^{60}$ which can be donated in a concerted fashion by an $\mathrm{H}$-atom donating antioxidant $\mathrm{AH}$ (equation 8), or can be provided separately by an electron-donating antioxidant (D) and a protic solvent SolvH (equation 9). ${ }^{61}$

$\mathrm{ROO} \bullet+\mathrm{AH} \rightarrow \mathrm{ROOH}+\mathrm{A} \bullet \quad($ Eq. 8)

$\mathrm{ROO} \bullet+\mathrm{D}+\mathrm{SolvH} \rightarrow \mathrm{ROOH}+\mathrm{D}^{\bullet+}+\mathrm{Solv}^{-} \quad$ (Eq. 9)

As a guide to understand the behavior of these nanomaterials, it is useful to consider that of simpler antioxidants. Phenols, diarylamines and ascorbate are well-known small-molecules antioxidants that possess weak N-H or O-H bonds and act as formal hydrogen-atom donors (equation 8). The bond 
dissociation enthalpy (BDE) of the phenolic $\mathrm{O}-\mathrm{H}$ group of $\alpha$-tocopherol is $78 \mathrm{kcal} / \mathrm{mol}$, i.e. it is much smaller than that of the ROO-H bond of alkyl hydroperoxides $(\mathrm{BDE} \approx 85 \mathrm{kcal} / \mathrm{mol}) .{ }^{62}$ These antioxidants can transfer at the same moment an electron and a proton to ROO• and are, therefore, very versatile, because they are active also in media in which protons are not available. Actually, this kind of antioxidants is active by different degrees in all media, ranging from apolar solvents to water. ${ }^{63}$ Nanoparticles having cleavable O-H groups on the surface, such as lignin and melanin ones, behave in a similar fashion (Scheme 3). Lignin nanoparticles, for instance, show antioxidant activity in apolar polymers such as natural rubber, ${ }^{64}$ as well as in methanol. ${ }^{65}$

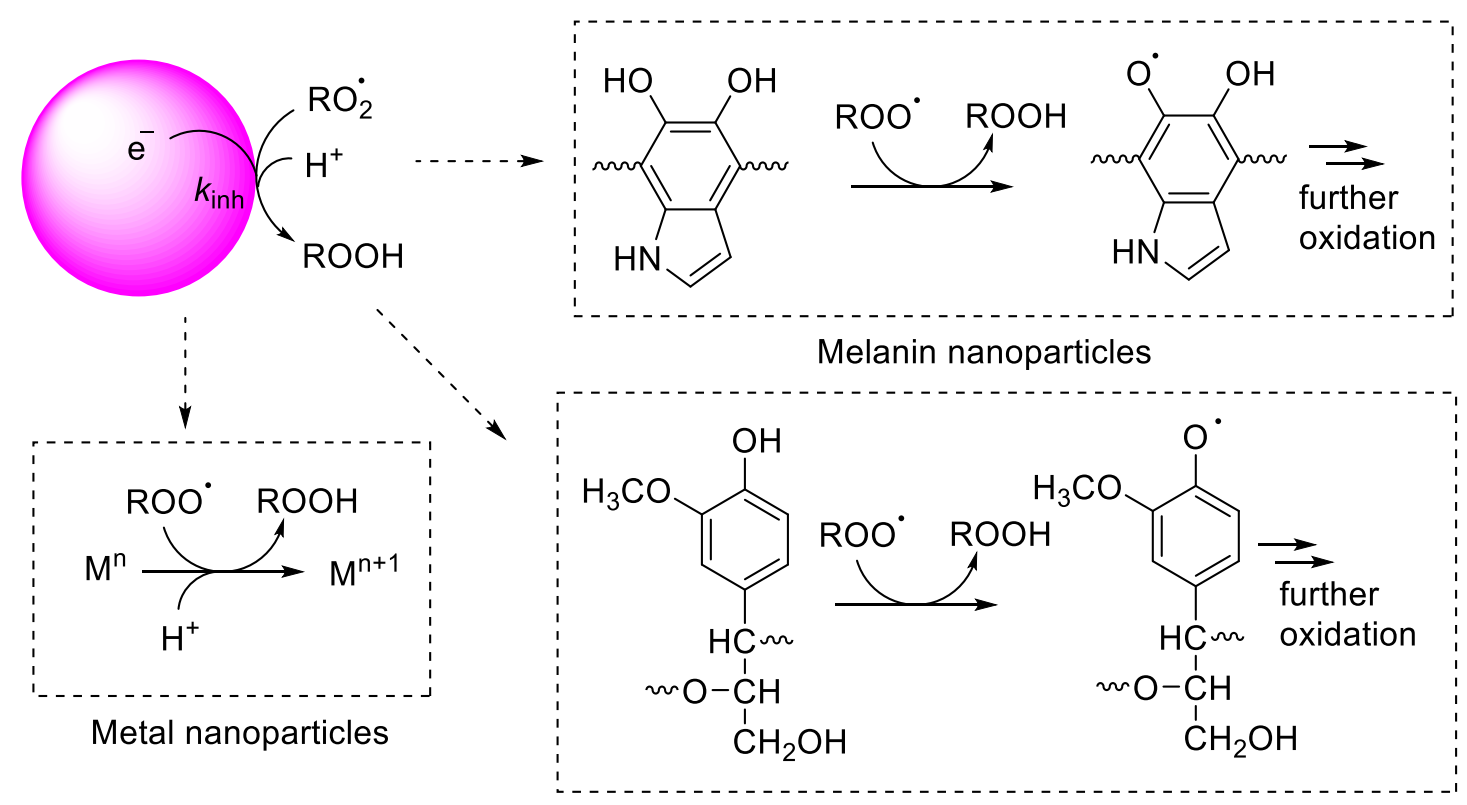

Lignin nanoparticles

Scheme 3. Chain-breaking activity of nanomaterials.

Beside formal $\mathrm{H}$-atom donors, also electron-donating molecules can potentially show chain-breaking activity, but their efficacy is strictly linked to the availability of $\mathrm{H}^{+}$in solution. The small-molecule antioxidant 2,2,6,6-(tetramethylpiperidin-1-yl)oxyl radical (TEMPO) can be taken as an example. TEMPO is a stable radical that easily donates an electron to form the corresponding oxoammonium cation (Scheme 4). 


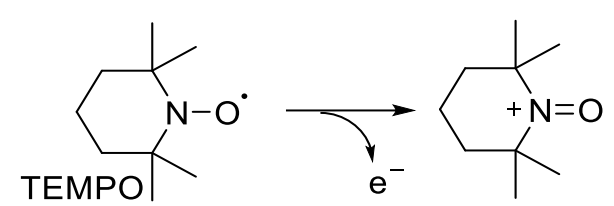

Scheme 4.

Interestingly, the antioxidant activity of TEMPO is negligible in aprotic solvents while it increases considerably upon addition of acids and in water, showing that radical quenching by TEMPO needs the availability of $\mathrm{H}^{+}$from the reaction medium. ${ }^{66,67}$ Similarly to TEMPO, many metal nanomaterials are good radical quenchers in aqueous systems thanks to the presence on their surface of electrondonating sites, which may be inherently present such as in cerium oxide ${ }^{68}$ and in platinum $\mathrm{NPs},{ }^{56}$ or they may be formed by UV-irradiation, as in case of titanium and zinc oxide nanoparticles. ${ }^{69}$

\section{3) INERT SCAFFOLD WITH ANTIOXIDANT FUNCTIONALITIES}

Despite the high number of currently known antioxidants, many challenges still exist in specific applications that include food technology, cosmetics and pharmaceutical technology or biomedical applications. Typical problems displayed by "traditional" small-molecule antioxidants are: their potential toxicity, their leaching or migration to unwanted compartments; their sensitivity to atmospheric oxygen, or to oxidase enzymes that causes loss of performance with time. Grafting smallmolecule antioxidants to nanomaterials has been recently proposed as an innovative way to improve their characteristics. Pristine nanomaterials should display absence of toxicity, low cost and facility of functionalization.

A proof-of-concept of the efficacy of antioxidants grafted to a nanomaterial was reported about ten years ago by Liu and co-workers, ${ }^{70}$ who attached Trolox, a synthetic analogue of $\alpha$-tocopherol, or salvianic $\operatorname{acid}^{71}$ to thiol-capped gold nanoparticles. The radical trapping ability of Au@Trolox was better than that of Trolox itself, suggesting that this strategy would not cause decrease of antioxidants 
properties. The food-grade antioxidants caffeic acid ${ }^{72}$ and gallic acid ${ }^{73}$ were covalently attached to $\mathrm{SiO}_{2} \mathrm{NPs}$ of different sizes by using aminopropyl-triethoxysilane (APTES) as the linker. Silica is considered biochemically inert, and finds use as flowing-aid for nutraceutical and pharmaceutical products. $\mathrm{SiO}_{2}$-linked gallic acid showed a good radical trapping ability, and could be reused without loss of activity. Interestingly, authors showed that after the reaction with free radicals, these nanoparticles underwent to significant agglomeration, presumably for the presence of cross coupling of the free radicals on the surface. ${ }^{74} \mathrm{~A}$ similar approach was used to link the phenolic antioxidants Trolox or curcumin on graphite-coated cobalt magnetic nanoparticles, ${ }^{75}$ or on the outer surface of halloysite nanotubes. ${ }^{76,77}$ Halloysite (HNTs) is a natural aluminosilicate clay, with a hollow tubular structure (up to $800 \mathrm{~nm}$ in length and $80 \mathrm{~nm}$ in external diameter) consisting of (moderately acidic) siloxane groups on the outer surface and (basic) aluminol at the inner surface, allowing different selectivity for molecules grafted in either surface. Curcumin was covalently linked on the surface of halloysite nanotubes by means of a disulfide bridge, which afforded thiol dependent release without compromising the ability of curcumin to trap free radicals. ${ }^{76}$ Trolox, a mimic of natural $\alpha$-tocopherol, was selectively grafted on the HNT external surface by using APTES as the linker (HNT-Trolox), while quercetin, a natural polyphenolic antioxidant, was loaded into the inner lumen to afford a bifunctional nanoantioxidant ${ }^{77}$ (see Figure 2). This material showed excellent antioxidant properties against the peroxidation of model substrates, which was explained as due to Trolox acting as main radical quencher, and quercetin functioning as co-antioxidant. 

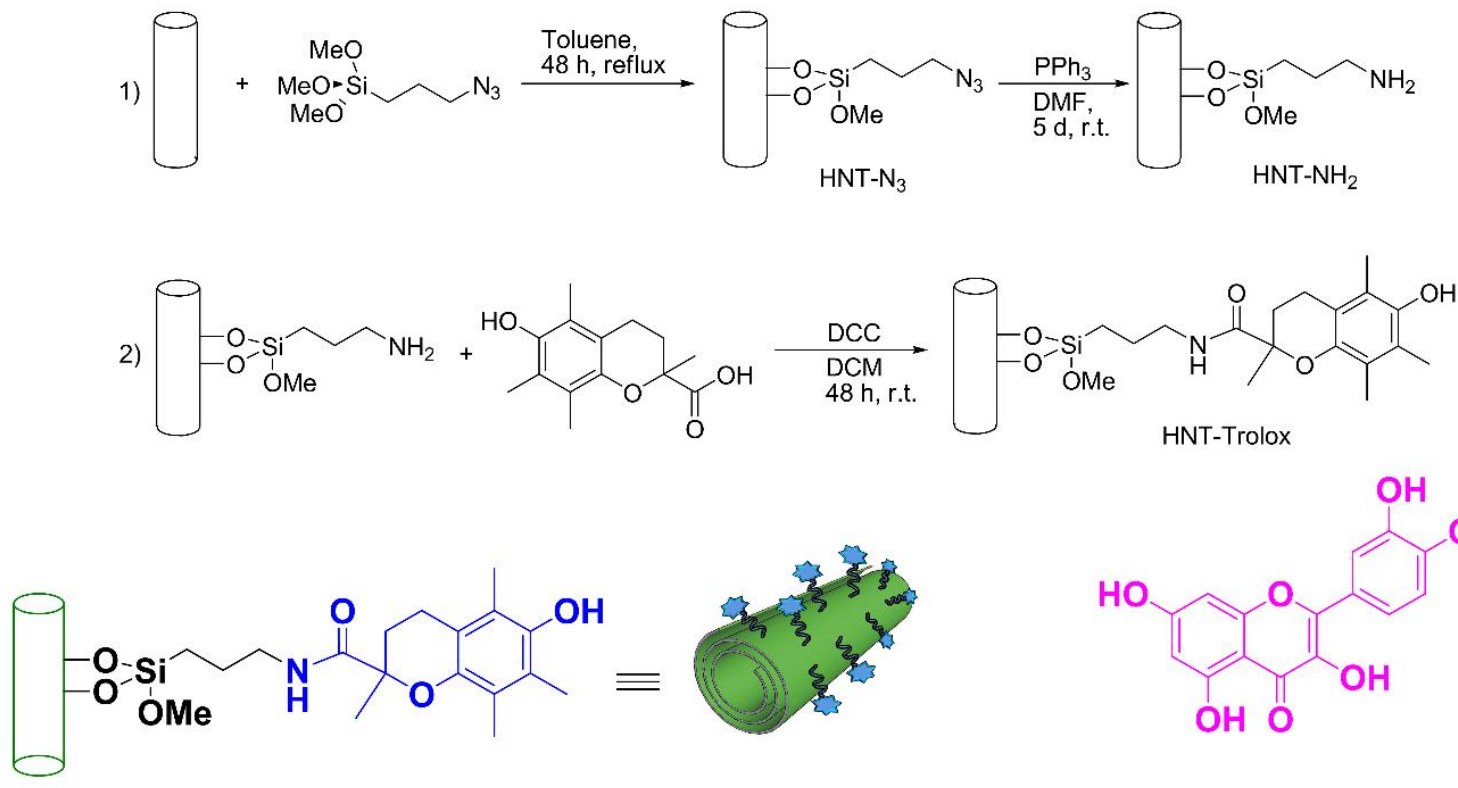

HNT-Trolox<smiles>C#COc1ccc(-c2oc3cc(O)cc(O)c3c(=O)c2O)cc1O</smiles>

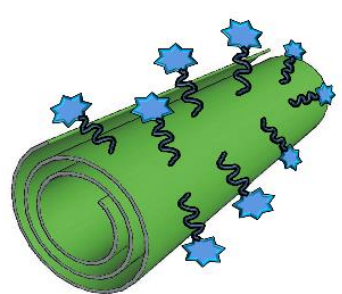

HNT-Trolox

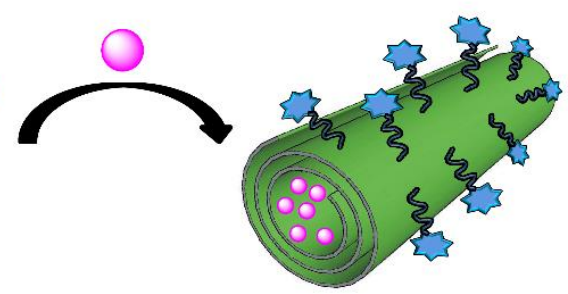

HNT-Trolox/Que

Figure 2. Upper part: procedure for grafting Trolox on the surface of halloysite nanotubes; lower part: loading of quercetin in the inner lumen of nanotubes. Reproduced from Ref. 77 with permission from The Royal Society of Chemistry.

However, the stoichiometry of radical trapping of HNT-Trolox was about 1, that is halved with respect of the factor of 2, which is observed for Trolox and is expected in the case of mono-phenolic antioxidants (see Scheme 1). This observation was explained as the effect of the cross coupling of the phenoxyl radicals of Trolox that hampers the trapping of the second radical by the antioxidant. It was proposed that quercetin included in the lumen of HNT prevents this side reaction and prolongs the antioxidant effect of the material. ${ }^{77}$

Other examples of antioxidant covalently bound to nanomaterials involve fullerenes and carbon nanotubes. These nanomaterials have a small intrinsic antioxidant activity, which is directed 
essentially toward $\mathrm{HO} \bullet$ and alkyl radicals. ${ }^{78}$ However, decorating their surface with small molecule antioxidants such as synthetic phenols ${ }^{79,80}$ or natural flavonoids ${ }^{81,82}$ can largely extend their antioxidant behavior by conveying peroxyl radical-trapping activity. Some examples are reported in Table 2.

Antioxidant enzymes can be linked or adsorbed on the surface of nanomaterial to improve their resistance to environmental effects, which could otherwise lead to denaturation and activity loss. Superoxide dismutase was adsorbed on the surface of a layered double hydroxide ${ }^{83}$ or on ceria nanoparticles ${ }^{84}$ without activity loss (see Table 2).

Table 2. Antioxidants supported by nanoparticles: mechanisms of action and chemical assays used to evaluate their activity.

\begin{tabular}{|c|c|c|c|}
\hline Nanoantioxidant & Action & Assay & Ref. \\
\hline $\begin{array}{l}\text { Curcumin linked to halloysite } \\
\text { nanotubes }\end{array}$ & $\begin{array}{l}\text { Chain } \\
\text { breaking }\end{array}$ & $\begin{array}{l}\text { Inhibited autoxidation } \mathrm{O}_{2} \text { consumption (pressure } \\
\text { sensor), DPPH (spectrophotometric) }\end{array}$ & 76 \\
\hline $\begin{array}{l}\text { Trolox linked to halloysite } \\
\text { nanotubes }\end{array}$ & $\begin{array}{l}\text { Chain } \\
\text { breaking }\end{array}$ & $\begin{array}{l}\text { Inhibited autoxidation } \mathrm{O}_{2} \text { consumption (pressure } \\
\text { sensor), DPPH (spectrophotometric) }\end{array}$ & 77 \\
\hline $\begin{array}{l}\text { Trolox linked to graphite-coated } \\
\text { Co magnetic NPs }\end{array}$ & $\begin{array}{l}\text { Chain } \\
\text { breaking }\end{array}$ & $\begin{array}{l}\text { Inhibited autoxidation } \mathrm{O}_{2} \text { consumption (pressure } \\
\text { sensor) }\end{array}$ & 75 \\
\hline $\begin{array}{l}\text { Caffeic acid or rutin linked to } \\
\text { mesoporous silica }\end{array}$ & $\begin{array}{l}\text { Chain } \\
\text { breaking }\end{array}$ & ORAC & 72 \\
\hline Trolox linked to Au NPs & $\begin{array}{l}\text { Chain } \\
\text { breaking }\end{array}$ & $\mathrm{DPPH} \bullet(\mathrm{EPR}$ detection $)$ & 70 \\
\hline Salvianic acid linked to Au NPs & $\begin{array}{l}\text { Chain } \\
\text { breaking }\end{array}$ & $\mathrm{DPPH} \cdot(\mathrm{EPR}$ detection $)$ & 71 \\
\hline $\begin{array}{l}\text { Gallic acid linked to } \mathrm{SiO}_{2} \text { coated } \\
\text { Ag NPs }\end{array}$ & $\begin{array}{l}\text { Chain } \\
\text { breaking }\end{array}$ & $\mathrm{DPPH} \bullet($ spectrophotometric and EPR) & 73 \\
\hline Gallic acid linked to $\mathrm{SiO}_{2} \mathrm{NPs}$ & $\begin{array}{l}\text { Chain } \\
\text { breaking }\end{array}$ & $\mathrm{DPPH} \bullet($ spectrophotometric and EPR) & 74 \\
\hline $\begin{array}{l}\text { BHT linked to single-walled } \\
\text { carbon nanotubes }\end{array}$ & $\begin{array}{l}\text { Chain } \\
\text { breaking }\end{array}$ & ORAC & 79 \\
\hline
\end{tabular}




\begin{tabular}{|l|l|l|l|}
\hline BHT linked to [60]fullerene & $\begin{array}{l}\text { Chain } \\
\text { breaking }\end{array}$ & $\begin{array}{l}\text { Inhibited autoxidation, } \mathrm{O}_{2} \text { consumption (pressure } \\
\text { sensor) }\end{array}$ & 80 \\
\hline $\begin{array}{l}\text { Flavonoids linked to } \\
\text { [60]fullerene }\end{array}$ & $\begin{array}{l}\text { Chain } \\
\text { breaking }\end{array}$ & $\begin{array}{l}\text { Inhibited autoxidation, } \mathrm{O}_{2} \text { consumption (pressure } \\
\text { sensor) }\end{array}$ & 81 \\
\hline $\begin{array}{l}\text { SOD adsorbed on layered double } \\
\text { hydroxide NPs }\end{array}$ & $\begin{array}{l}\text { SOD } \\
\text { mimics }\end{array}$ & $\begin{array}{l}\text { Xanthine and xanthine oxidase, nitroblue } \\
\text { tetrazolium (spectrophotometric) }\end{array}$ & 82 \\
\hline SOD adsorbed on Ce Nps & $\begin{array}{l}\text { SOD } \\
\text { mimics }\end{array}$ & $\begin{array}{l}\text { Xanthine and xanthine oxidase, hydrosoluble } \\
\text { tetrazolium salt (spectrophotometric) }\end{array}$ & 84 \\
\hline CAT adsorbed on Ce Nps & $\begin{array}{l}\text { CAT } \\
\text { mimics }\end{array}$ & Amplex red assay & 84 \\
\hline
\end{tabular}

\section{4) CHEMICAL METHODS TO MEASURE ANTIOXIDANT ACTIVITY}

\subsection{Catalase activity}

Catalase activity of nanoantioxidants (equation 1) is measured by assessing the decrease of the $\mathrm{H}_{2} \mathrm{O}_{2}$ concentration and the formation of $\mathrm{O}_{2}$ from $\mathrm{H}_{2} \mathrm{O}_{2}$. One of the most popular methods to measure $\mathrm{H}_{2} \mathrm{O}_{2}$ concentration consists in following the absorbance change of the solution at $240 \mathrm{~nm}$. The absorption spectrum of hydrogen peroxide, measured from 200 to $400 \mathrm{~nm}$, is shown in Figure $3 \mathrm{~A} .{ }^{85}$ Although $\mathrm{H}_{2} \mathrm{O}_{2}$ does not have an absorbance maximum at $240 \mathrm{~nm}$, this wavelength is chosen as a compromise between sensitivity, interferences of other substances in solution, and degradation of $\mathrm{H}_{2} \mathrm{O}_{2}$ due to the UV beam used by the spectrophotometer. The extinction coefficient at $240 \mathrm{~nm}$ is $43.6 \mathrm{M}^{-1} \mathrm{~cm}^{-1}$. ${ }^{86}$ 
A

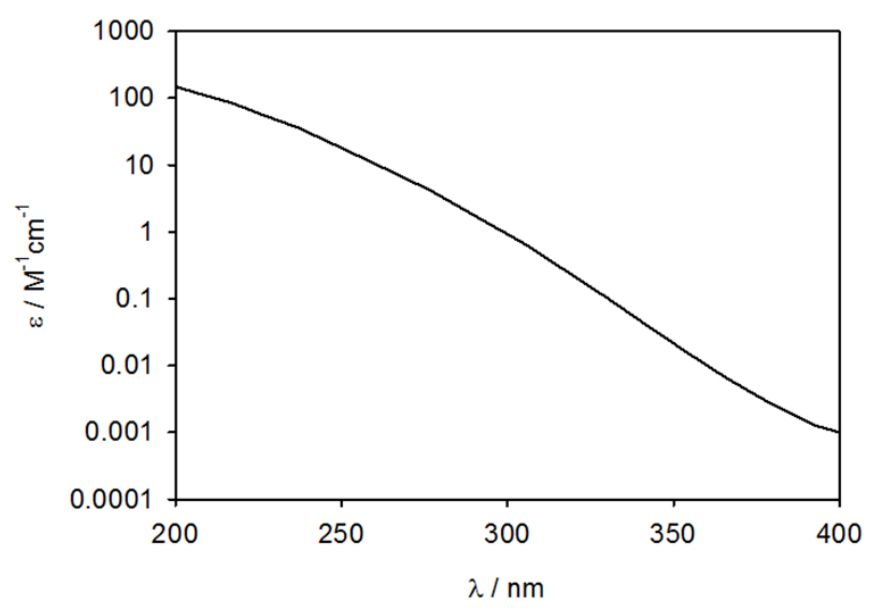

C<smiles>CC(=O)N1c2ccc(O)cc2Oc2cc(O)ccc21</smiles>

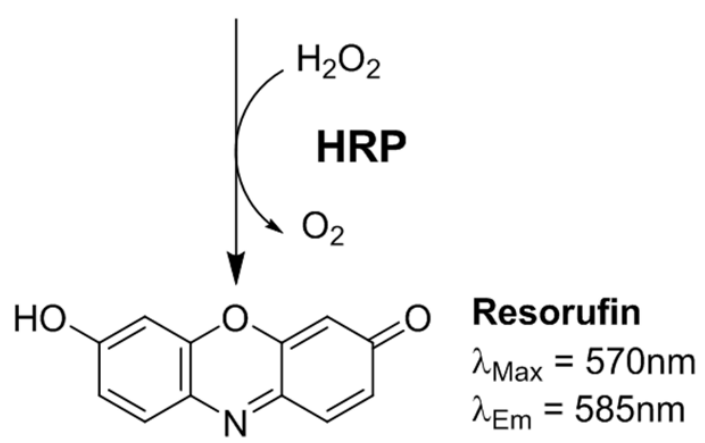

B<smiles>CC1(C)OB(c2ccc3c(=O)c4ccc(B5OC(C)(C)C(C)(C)O5)cc4oc3c2)OC1(C)C</smiles><smiles>O=c1c2ccc(O)cc2oc2cc(O)ccc12</smiles>

red fluorescence<smiles>Cc1cc(C2(c3cc(C)c(O)c(CN(CC(=O)O[Na])CC(=O)O[Na])c3)OS(=O)(=O)c3ccccc32)cc(CN(CC(=O)O[Na])CC(=O)O[Na])c1O</smiles>

Figure 3. A) UV absorption curve of hydrogen peroxide in distilled water. $\varepsilon=$ molar extinction coefficient (data taken from ref.85). B) Sensor for $\mathrm{H}_{2} \mathrm{O}_{2}$ based on the cleavage of a boronate group. ${ }^{87}$ C) Mechanism underlying Amplex Red detection of $\mathrm{H}_{2} \mathrm{O}_{2}$. D) Iron-chelating agent xylenol orange.

This method is suitable to measure catalase-like activity for systems in which there are no other strongly absorbing species at $240 \mathrm{~nm}$, and when interferences due to light scattering in the sample (e.g. due to suspended nanomaterials) are small and constant during the reaction course. In order to improve the sensitivity and make the spectrophotometric detection possible in a broader range of samples, methods based on the reaction with a probe have also been developed. The ferrous xylenol orange assay relies upon the rapid hydroperoxide-mediated oxidation of $\mathrm{Fe}^{2+}$ under acidic conditions. The product $\mathrm{Fe}^{3+}$ forms a chromophore with xylenol orange which absorbs strongly at $560 \mathrm{~nm}$ (Figure 
3D). Although this method detects lower concentrations of $\mathrm{H}_{2} \mathrm{O}_{2}$, it is plagued by the interference of reducing agents (such as ascorbic acid and glutathione), that can bring back $\mathrm{Fe}^{3+}$ to $\mathrm{Fe}^{2+}$. Therefore, it should be used with caution when assessing hydroperoxide levels in the presence of antioxidants. ${ }^{88}$ The Amplex ${ }^{\circledR}$ Red assay is based on the reaction of $\mathrm{H}_{2} \mathrm{O}_{2}$ with $\mathrm{N}$-acetyl-3,7-dihydroxyphenoxazine in the presence of horseradish peroxidase (HRP), to form a colored and fluorescent product, resorufine (Figure 3C). ${ }^{89}$ Limitations of this assay include the interference by reducing agents and Amplex Red decomposition by light. ${ }^{90}$ Probes based on the reaction of $\mathrm{H}_{2} \mathrm{O}_{2}$ with boronate esters have been developed to overcome the problems of low sensitivity and interferences. In this approach, a boronate ester is implemented in the structure of a dye to quench its fluorescence emission, and the reaction of $\mathrm{H}_{2} \mathrm{O}_{2}$ with the boronate group triggers a fluorescence turn-on response. (Figure $3 \mathrm{~B}$ ) The recent developments of this technique have been reviewed. ${ }^{91}$

A conceptually simple approach to follow catalase activity consists in monitoring $\mathrm{O}_{2}$ evolution during the reaction: visual detection of bubbles formation is a qualitative method often employed to rapidly assess catalase activity of nanomaterials. For instance, in Figure 4A, formation of $\mathrm{O}_{2}$ inside of EPR (electron paramagnetic resonance) tubes when mixing $\mathrm{H}_{2} \mathrm{O}_{2}$ and various kinds of Au nanoparticles is reported. ${ }^{24}$ Quantitative CAT activity have been obtained with minimal equipment by monitoring the height of foam formation inside test tubes in the presence of the neutral surfactant Triton X-100, upon calibration with standard CAT solutions. $^{92}$

Polarographic sensors based on a Clark electrode are the most common methods to determine $\mathrm{O}_{2}$ formation. As they are suited to measure $\mathrm{O}_{2}$ concentration in real time, polarographic probes provide the rate of $\mathrm{O}_{2}$ formation and therefore allow to get kinetic insights. ${ }^{28}$ However, the main limitation of this method is the low solubility of $\mathrm{O}_{2}$ in water, which results in bubble formation when this limit is surpassed. 

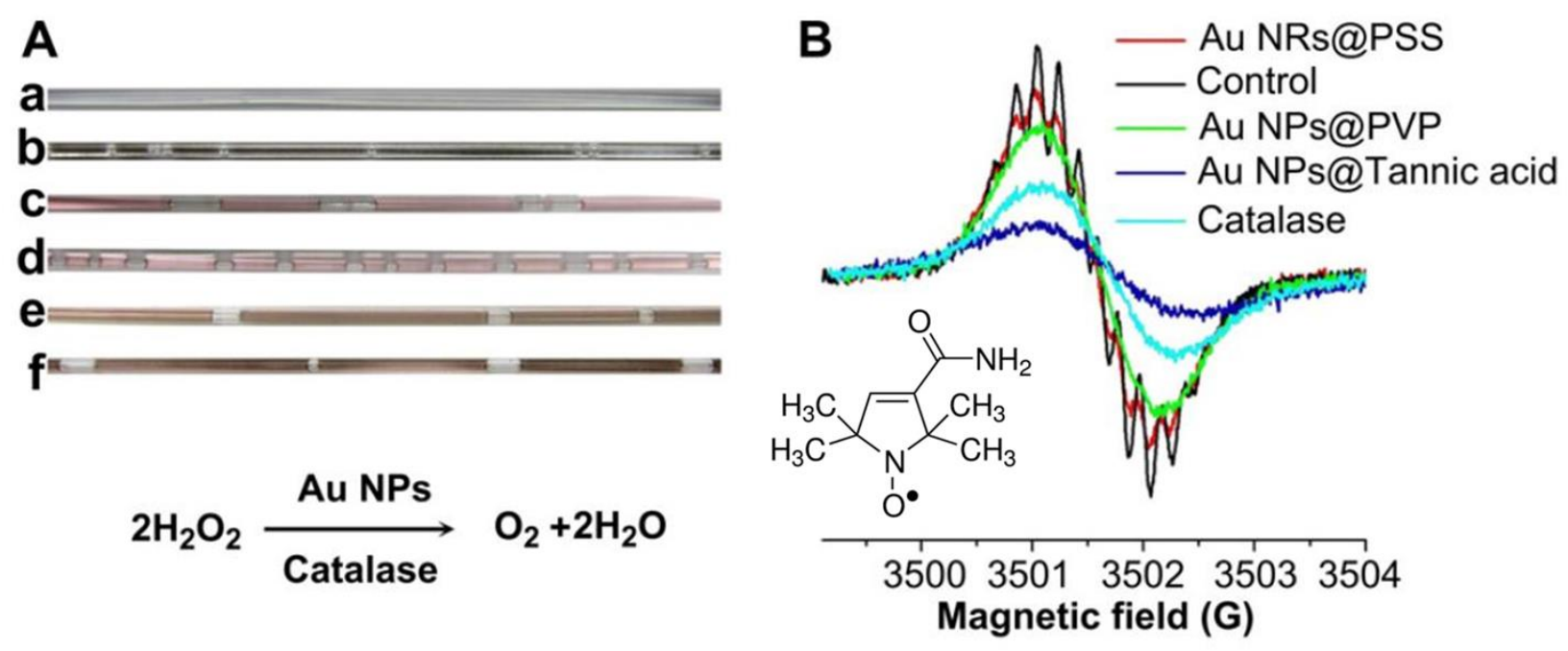

Figure 4. The catalase-like activity of Au NPs. (A) Observation of the $\mathrm{O}_{2}$ bubbles generated at 15 min in $0.5 \mathrm{mM} \mathrm{H}_{2} \mathrm{O}_{2}$ without catalyst (a); with $5 \mathrm{U} / \mathrm{mL}$ catalase (b); with $10 \mathrm{~nm} \mathrm{Au}$ NPs coated with polyvinylpyrrolidone (c); with $10 \mathrm{~nm}$ Au NPs coated with tannic acid (d); with Au nanorods (NRs) coated with polystyrenesulfonate (e), or coated with poly(diallyldimethylammoniumchloride) (f). (B) EPR spectra of 2,2,5,5-tetramethyl-3-pyrroline-3-carboxamide (CTPO) in absence or presence of catalysts in a closed chamber. Samples contained $0.1 \mathrm{mM} \mathrm{CTPO,} 0.5 \mathrm{mM} \mathrm{H}_{2} \mathrm{O}_{2}$ mixed without or with Au NPs $(0.1 \mathrm{mg} / \mathrm{mL})$ or $5 \mathrm{U} / \mathrm{mL}$ catalase in $\mathrm{pH} 11.0$ buffer. Spectra were collected after $4 \mathrm{~min}$ of incubation. Reproduced from Ref. 24 with permission from Elsevier.

Another method to determine dissolved $\mathrm{O}_{2}$ is the measurement of spectral line broadening by EPR spectroscopy. This experiment requires the presence of a suitable spin-probe, usually a stable and water-soluble dialkylnitroxide (see for instance Figure 4B). The line broadening is brought about by the magnetic interaction upon oxygen-radical collisions, often referred to as "Heisenberg spin exchance". ${ }^{93}$ In figure 4B, the line broadening effect together with the loss of hyperfine structure of the EPR signal of a nitroxide spin probe due to the catalase activity of AuNPs is shown. As a general remark valid also for all enzyme-like activities, the CAT activity of a nanomaterial should be 
compared to that of the natural enzyme, in order to allow a meaningful ranking of CAT-like ability of the nanomaterial.

\subsection{Glutathione peroxidase (GPX) activity}

The GPX-like activity can be measured indirectly by a coupled reaction with glutathione reductase (GR) (see Figure 5). Oxidized glutathione (GSSG), produced upon reduction of hydroperoxides by GPX, is recycled to its reduced state (GSH) by GR using NADPH as the reducing agent. The oxidation of NADPH to NADP ${ }^{+}$is accompanied by a decrease in absorbance at $340 \mathrm{~nm}$.
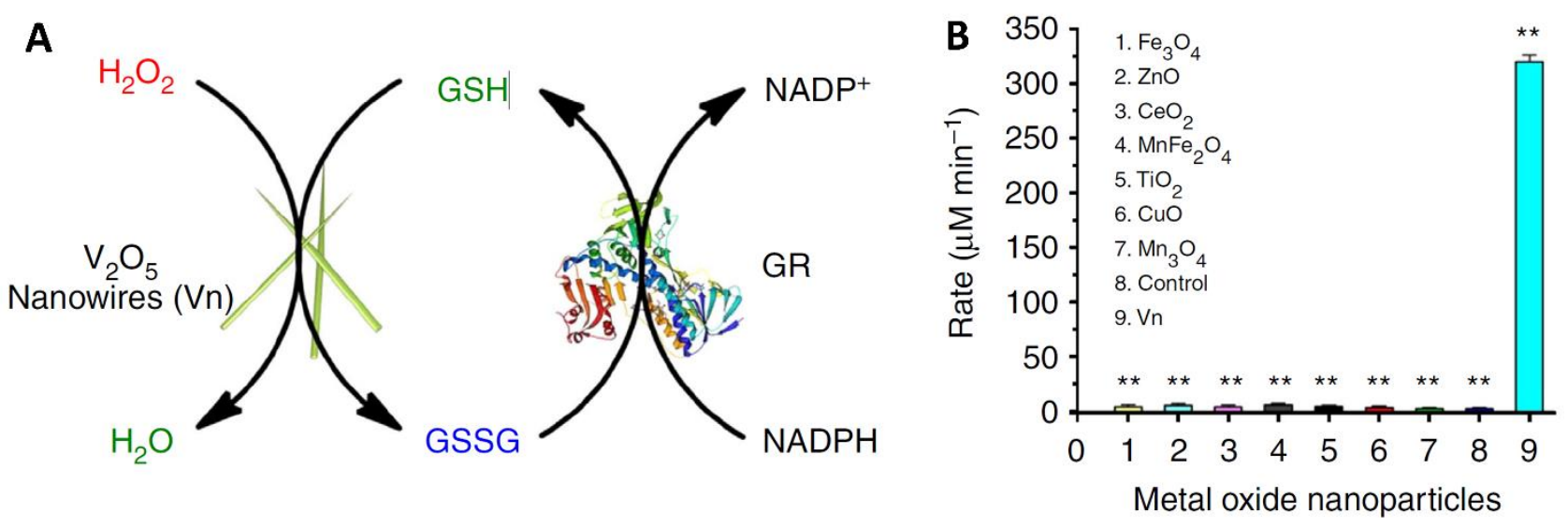

Figure 5. GPX-like activity of vanadium oxide nanowires measured by GR coupled assay. A) Reaction scheme of the assay; B) Plot of the initial rate of NADPH consumption showing the unicity of the GPX-like activity of $\mathrm{V}_{2} \mathrm{O}_{5}$ among metal oxide nanomaterials. Reproduced from Ref. 41 by permission of Springer Nature, 2014.

In organic solvents, and in any case in which the GR-coupled method cannot be applied because of the instability of the enzyme, thiol peroxidase activity can be measured by using thiophenol as reducing agent instead of GSH. This assay consists in mixing $\mathrm{H}_{2} \mathrm{O}_{2}$, thiophenol and the catalyst in methanol, and in monitoring the UV absorption of product diphenyl disulfide at $305 \mathrm{~nm} .{ }^{94}$ 


\subsection{SOD-like activity}

SOD activity can be assessed by generating a certain concentration of superoxide in the sample, and by detecting its level by means of a suitable probe. The most common source of superoxide is the molybdo-flavin enzyme xanthine oxidase $(\mathrm{XO})$, which catalyzes the reaction between xanthine $(\mathrm{X})$ and $\mathrm{O}_{2}$ to form uric acid and a mixture of $\mathrm{O}_{2}{ }^{-} / \mathrm{H}_{2} \mathrm{O}_{2}$. Under nearly physiologic conditions $\left(21 \% \mathrm{O}_{2}\right.$ and $\mathrm{pH}=7.0) \mathrm{XO}$ catalyzes the reduction of $\mathrm{O}_{2}$ to $\mathrm{H}_{2} \mathrm{O}_{2}$ and $\mathrm{O}_{2}{ }^{--}$in a ratio of about $3: 1 ;{ }^{95}$ therefore, this method produces more $\mathrm{H}_{2} \mathrm{O}_{2}$ than superoxide. Another useful source of superoxide is its potassium salt, $\mathrm{KO}_{2}$, which can be solubilized in polar aprotic organic solvents (i.e. dimethylsulfoxide) with the help of a crown ether (18-crown-6) and stored for relatively long time under strictly anhydrous conditions ${ }^{50}$ Superoxide itself can not be easily detected, because it absorbs at low wavelengths and with a low extinction coefficient $\left(\varepsilon_{270 \mathrm{~nm}}=1330 \mathrm{M}^{-1} \mathrm{~cm}^{-1}\right)$. Its disappearance can instead be followed by its reaction with probes, which form stable products that can be analyzed by UV-vis or EPR spectroscopies. The most common probes are those based on water soluble tetrazolium salts (such as iodonitrotetrazolium chloride), which are reduced by $\mathrm{O}_{2}^{\cdot-}$ to highly absorbing formazan dyes (see Figure 6A). ${ }^{96,97}$ Alternatively, superoxide can be detected by following the absorption change at $550 \mathrm{~nm}$ due to the reduction of cytochrome c. ${ }^{98}$ However, as hydrogen peroxide, formed directly or as a product of superoxide dismutation, can oxidize back cytochrome c at rates comparable to those at which it is reduced by superoxide, this assay may underestimate the superoxide level. This problem can be partly reduced by adding catalase to the reaction. ${ }^{99}$ 
A

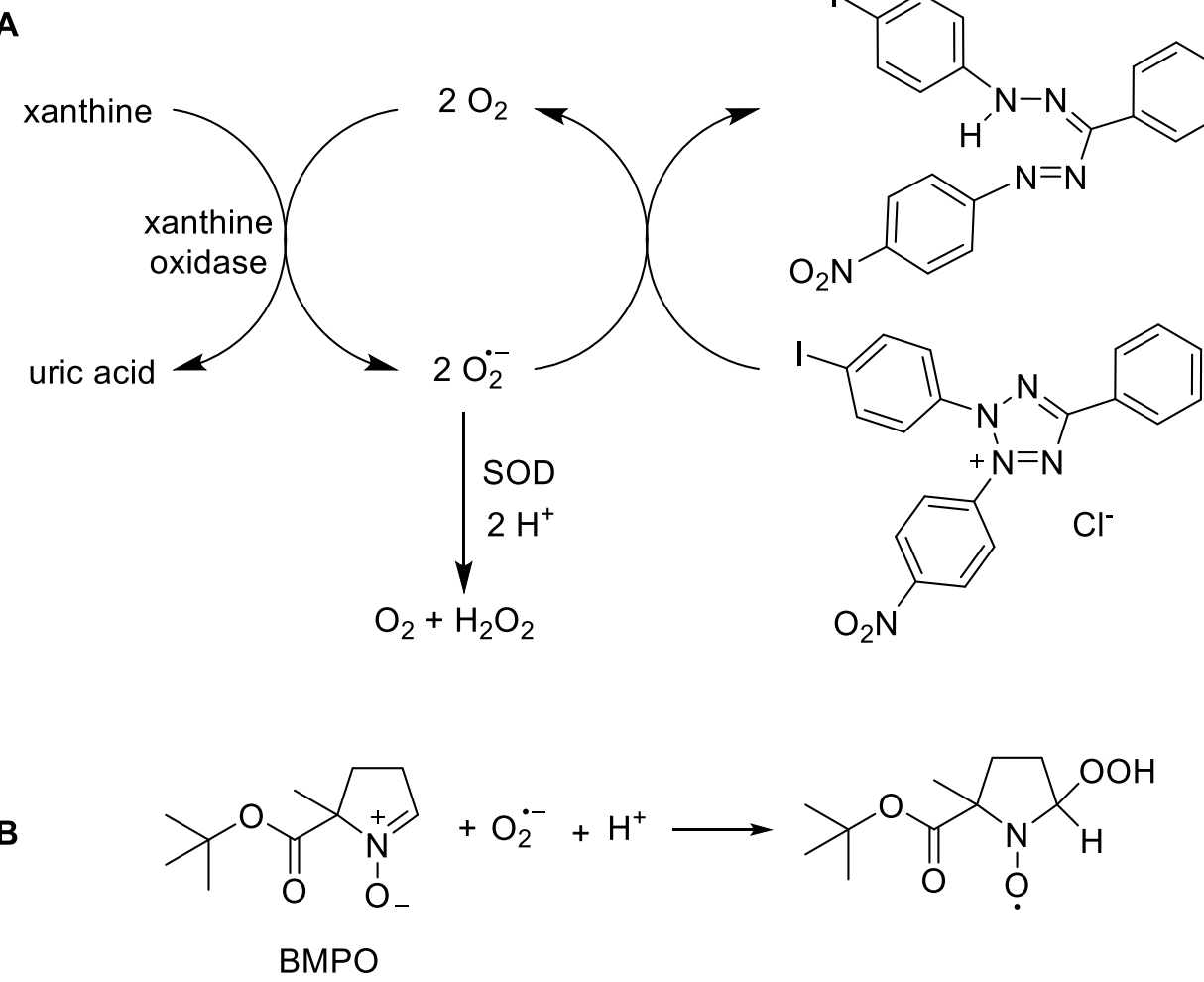

Figure 6. Methods to detect superoxide. A) reduction of iodonitrotetrazolium chloride to a formazan dye; B) formation of a nitroxyl radical adduct between BMPO and superoxide.

EPR detection of $\mathrm{O}_{2}{ }^{-}$is based on the reaction of this radical with a nitrone, which forms a persistent nitroxyl radical that can be spectroscopically quantified. The detection of superoxide requires suited spin traps, such as 5-tert-butoxycarbonyl-5-methyl-1-pyrroline-N-oxide (BMPO, see Figure 6B), or 5-diethoxyphosphoryl-5-methyl-1-pyrroline-N-oxide (DEPMPO), which afford relatively stable adducts with superoxide. In fact, the adduct with 5,5-dimethyl-1-pyrroline N-oxide (DMPO), one of the most frequently used spin traps in free radical biology, spontaneously decays to the DMPOhydroxyl adduct in short times, making quantitation of superoxide by this spin trap nearly impossible. ${ }^{100}$ 


\subsection{Chain-breaking antioxidant activity}

Chain-breaking antioxidant activity describes the ability to trap alkylperoxyl radicals (ROO•), that are the chain-carrying species of peroxidation reactions. These assays can be divided into three broad families, listed in order of descending similarity with real systems: i) inhibited autoxidation, ii) competitive probe reaction, and iii) indirect methods.

Inhibited autoxidation methods are based on the comparison between the extent of the autoxidation of the substrate, both in the presence and in the absence of antioxidants. The oxidizable substrate may be represented by purified natural compounds (e.g. linoleic acid and its esters, phosphatidylcholine, 7-dehydrocholesterol), or by pure synthetic chemicals (styrene, cumene, tetrahydrofuran). The initiation of the autoxidation is usually induced by adding azo-initiators, such as the lipid-soluble AIBN (2,2'-azobis-isobutyronitrile), or water-soluble AAPH ((2,2'-azobis(2amidinopropane) dihydrochloride). Their homolytic decomposition proceeds at a constant rate at a given temperature during the entire course of autoxidation, providing a constant rate of initiation. On the other hand, other kinds of initiation (spontaneous, or by means of iron and copper ions mixed to $\mathrm{H}_{2} \mathrm{O}_{2}$ ) are less reproducible. Methods based on inhibited autoxidation, mainly differ in the way the reaction is monitored.

The measure of $\mathrm{O}_{2}$ consumption is perhaps the easiest way to follow an autoxidation reaction and it can be performed by various methods: by using a pressure sensor, ${ }^{75,76,80}$ a Clark electrode ${ }^{56}$ or by measuring the line broadening by EPR spectroscopy. ${ }^{56,59}$ These methods provide a quantitative measurement of the rate constant and the stoichiometry of the reaction of an antioxidant with ROO• radicals. Interestingly, oximetry methods do not suffer from interferences due to the strong optical absorption of nanomaterials that instead limits the use of methods based on spectrophotometric measurements (Figure 7). ${ }^{101}$ The analysis of the $\mathrm{O}_{2}$ consumption plots, such as those reported in Figure 7, provides two fundamental parameters that describe the chain-breaking antioxidant activity: the rate constant for the reaction with $\mathrm{ROO} \bullet$ and the stoichiometry of radical trapping. ${ }^{8}$ 

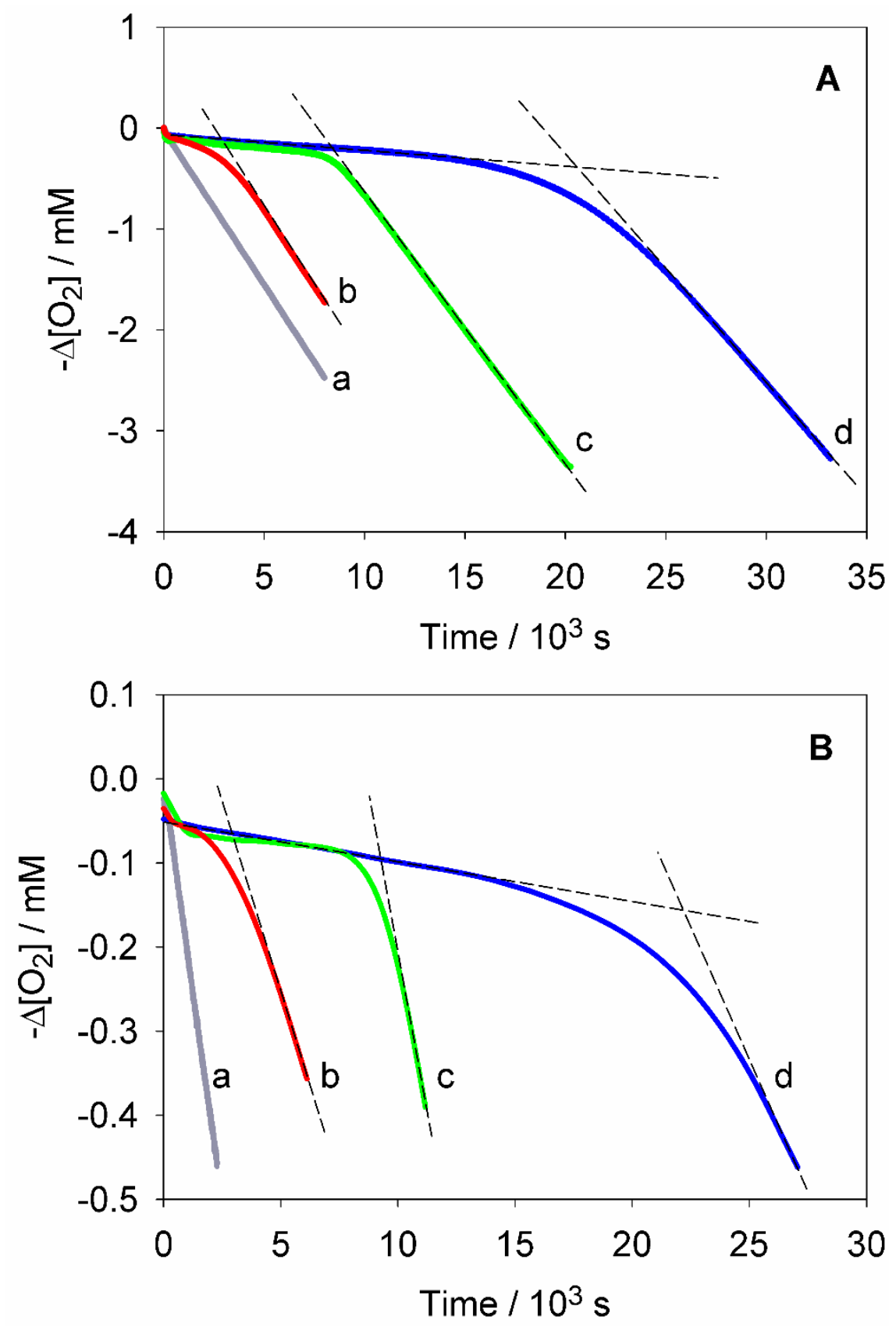

Figure 7. Inhibition of the autoxidation of cumene in acetonitrile (A) or chlorobenzene (B) by $0.1 \mathrm{mg}$ $\mathrm{mL}^{-1}$ of: halloysite nanotubes (HNT) (a), HNT loaded with quercetin (b), Trolox-grafted HNT (c) and Trolox-grafted HNT loaded with quercetin (d). Measures were performed by a pressure sensor. For the structures, see Figure 2. Reproduced from Ref. 77 with permission from The Royal Society of Chemistry. 
Other methods to monitor the autoxidation reaction include the measure of hydroperoxides (the primary oxidation products) or the formation of late oxidation products, such as carbonyl compounds. The TBARS (thiobarbituric acid reactive species) assay is a semi-quantitative colorimetric method used to follow the autoxidation of polyunsaturated lipids. It is based on the reaction of 2-thiobarbituric acid (TBA) with malondialdehyde (MDA), which is one of the late oxidation products deriving from the decomposition or subsequent oxidation of hydroperoxides. The detection of late oxidation products like MDA suffers from limitations as compared to the monitoring of hydroperoxides formation or oxygen consumption, in that it does not allow to monitor the actual kinetics of the autoxidation reaction. Actually, such methods like the TBARS are typically applied in a "single point" fashion, i.e. the formation of oxidation products is assayed only after a fixed time: unfortunately, such approach can only provide qualitative information concerning the occurrence of autoxidation. Although it is common practice in the scientific literature to base the quantitative evaluation of antioxidants on the measurements of TBARS or other late oxidation products in a model system, we would like to warn on the dangers of this approach, as the amount of carbonyl compounds detected in the reaction mixtures is influenced by a number of experimental variables that are far beyond the effectiveness of the tested antioxidant. An in-depth discussion on these aspects has recently been provided. ${ }^{8}$

In competitive probe reaction assays, antioxidants prevent the reaction between ROO• radicals and an oxidizable probe, whose reaction can be easily detected by some spectroscopic techniques. The most popular method of this category is the ORAC (oxygen-radical antioxidant capacity) assay, in which the antioxidant competes with a fluorescent probe (fluorescein) for quenching peroxyl radicals generated from AAPH (Scheme 5) ${ }^{57,72}$ After reacting with peroxyl radicals, emission at $520 \mathrm{~nm}$ of fluorescein decreases and the antioxidant activity is determined by the area-under-the curve of the intensity vs. time plot. 

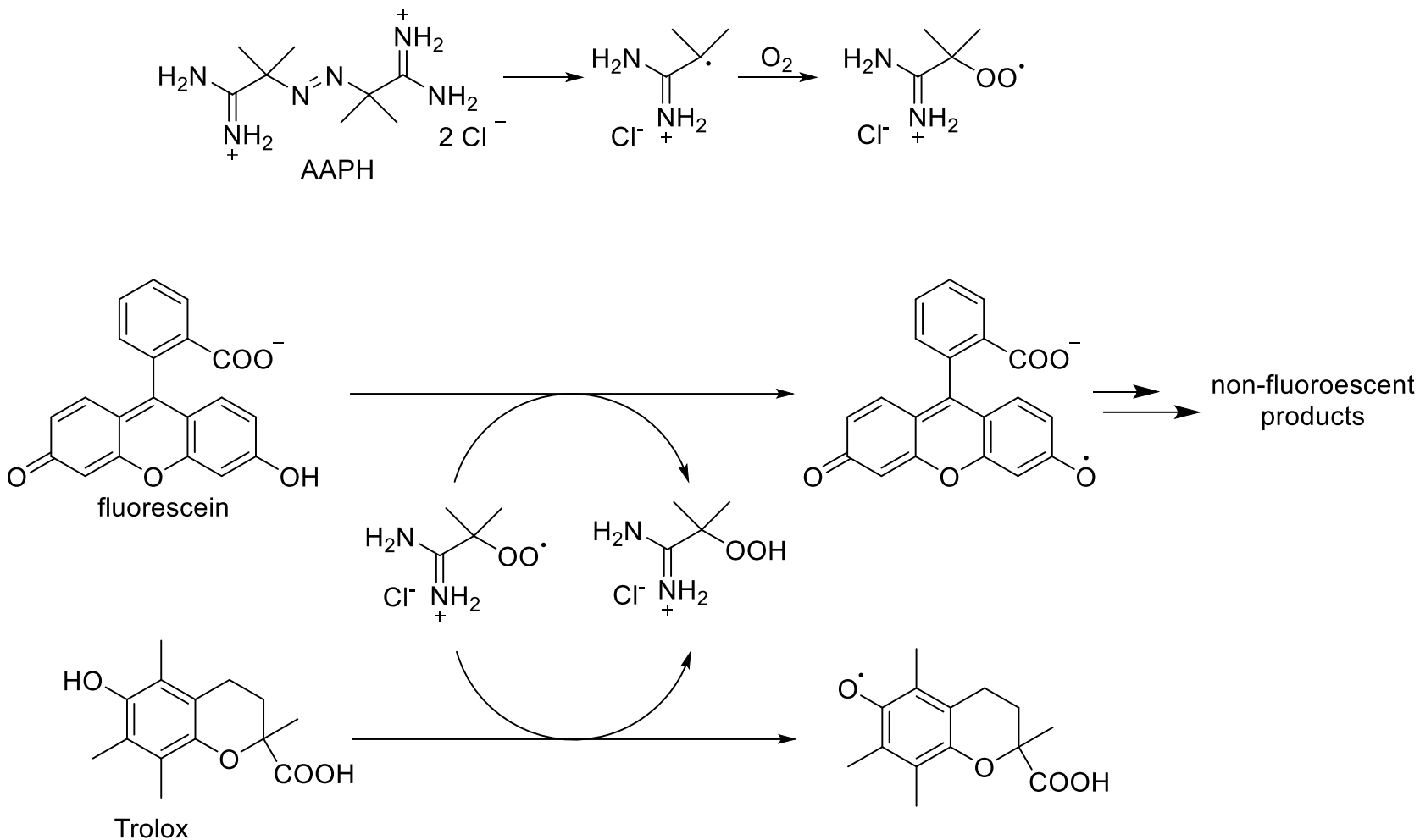

Scheme 5. Radical chemistry underlying the ORAC assay. The water-soluble azoinitiator AAPH forms alkylperoxyl radicals that react with fluorescein causing the loss of its fluorescence. In the presence of antioxidants, such as the vitamin E analogue Trolox, the fluorescence loss is slowed down.

An alternative probe is represented by spin-traps able to afford stable adduct with peroxyl radicals, which can be detected by EPR spectroscopy. Because of the absence of an oxidizable substrate and of the lack of a kinetic analysis of the results, these methods provide only a semi-quantitative estimation of the antioxidant activity. In particular, the area-under-the-curve approach merges in unique value two distinct aspects of the antioxidant activity, i.e. the rate and the stoichiometry of the reaction with $\mathrm{ROO} \bullet$; therefore, it should be used with caution in chemical-physical studies. ${ }^{8}$

Indirect methods are based on the reaction of the antioxidant with a stable radical, whose disappearance can be followed by spectroscopic techniques. EPR detection avoids interferences due to light scattering (Figure 8). Some colored radicals and radical precursors have been developed for 
this purpose, such as 2,2-diphenyl-1-picrylhydrazyl (DPPH•) and 2,2'-azino-bis(3ethylbenzothiazoline-6-sulphonic acid) (ABTS). These methods are very popular, although their limitations make them suitable only for preliminary screening procedures. The probes are chemically different from the peroxyl radicals formed during autoxidation of real systems, and, due to the experimental design, it is hard to establish whether the investigated compound can actually interrupt the chain reaction of autoxidation, or it is simply able to reduce the chosen probe. For instance, even $\mathrm{H}_{2} \mathrm{O}_{2}$, that can hardly be considered an antioxidant, is able to bleach DPPH•, presumably with the formation of superoxide as intermediate. ${ }^{102}$ Therefore, a good score in these indirect assays, on its own cannot be taken as a proof of antioxidant activity. ${ }^{8}$ Nevertheless, DPPH• and inhibited autoxidation methods can fruitfully be used together to have a clearer picture of both the reactivity and the stoichiometry of radicals trapping by the nanoantioxidants. ${ }^{77}$
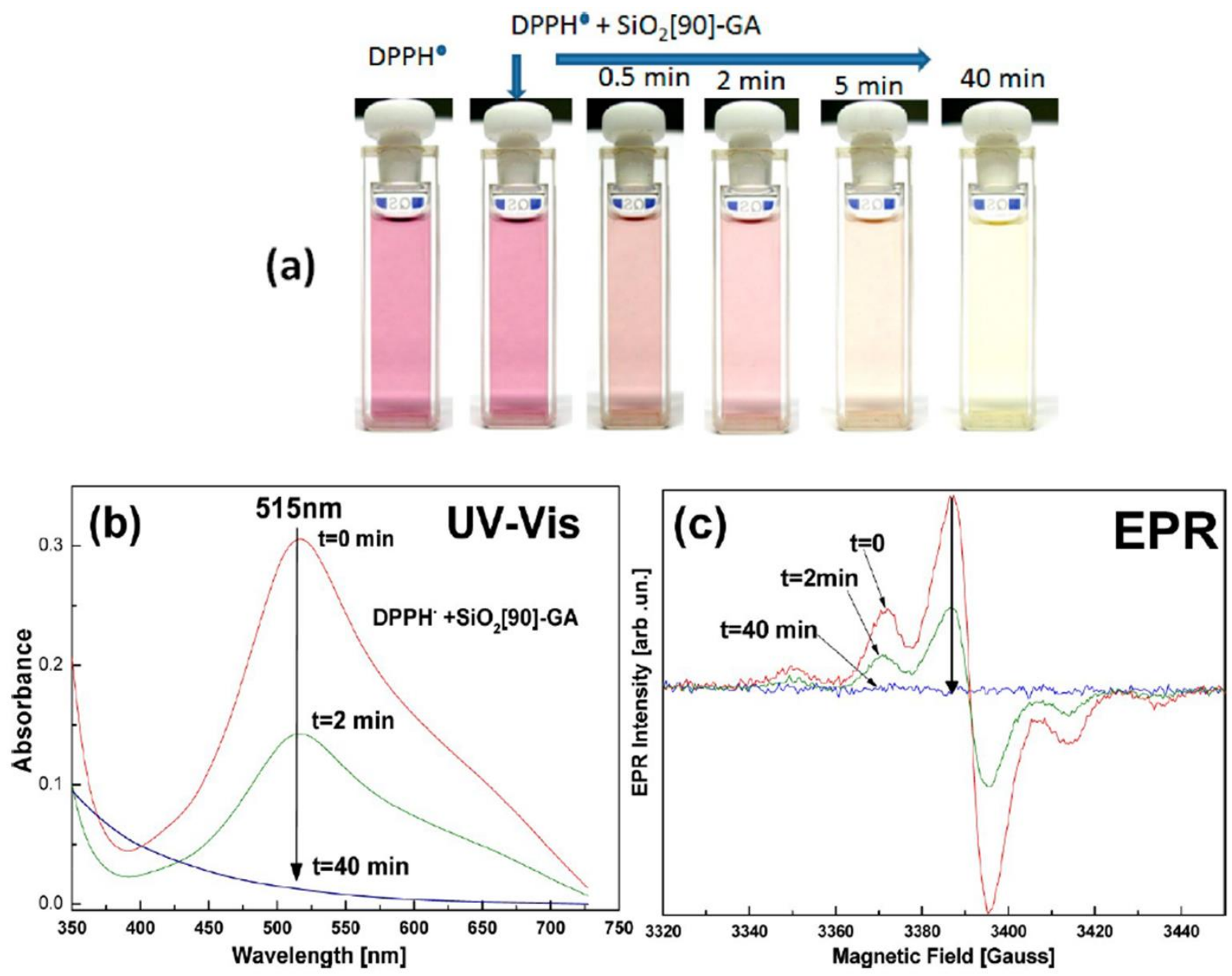
Figure 8. (a) Decolorization of the DPPH• radicals in methanol reacting $\mathrm{SiO}_{2}-\mathrm{GA}$ NPs. (b) Timedecay of UV-vis absorption and (c) the EPR signal the DPPH $\bullet$ radicals interacting with $\mathrm{SiO}_{2}-\mathrm{GA}$ NPs in methanol. GA = gallic acid. Reprinted with permission from Ref 74. Copyright 2012 American Chemical Society.

\subsection{Other methods}

4.5.1 Hydroperoxyl radicals quenching. The $\mathrm{HO} \bullet$ radical is often encountered as initiating radical and as source of damage on biomolecules such as DNA and proteins. However, given its extreme reactivity toward all organic substrates, the possibility that an antioxidant traps it before it attacks the substrate is expected to be small in most systems. ${ }^{8}$ The 2-deoxyribose assay is a common method used to determine the ability to quench $\mathrm{HO} \bullet$ radicals. This assay consists in incubating 2-deoxyribose with a Fe ${ }^{3+}$ salt, $\mathrm{H}_{2} \mathrm{O}_{2}$ and ascorbic acid, which acts as reductant and generates the catalytically active $\mathrm{Fe}^{2+}$ ion. The $\mathrm{HO} \cdot$ radicals are then produced by the Fenton reaction between $\mathrm{Fe}^{2+}$ and $\mathrm{H}_{2} \mathrm{O}_{2}$ (see equation 2). The oxidation of the sugar is followed by measuring the absorbance of the solution after the addition of thiobarbituric acid (TBA). The activity of the HO• quencher is assessed as the ability to prevent the oxidation of 2-deoxyribose. ${ }^{103}$ The level of $\mathrm{HO} \cdot$ present in solution can be estimated also by measuring its reaction with a colored probe, such as the chromogenic reagent methyl violet, which has a maximum absorbance at about $582 \mathrm{~nm} .{ }^{104}$ Alternatively, HO• can be detected via its reaction with a spin trap such as 5,5-dimethyl-pyrroline N-oxide (DMPO), by using EPR spectroscopy. ${ }^{105}$

4.5.2. Singlet oxygen $\left({ }^{1} \mathrm{O}_{2}\right)$. It is a powerful oxidizer which is formed after the energy transfer from an excited photosensitizer to ground-state, triplet $\mathrm{O}_{2}$. It causes the non-radical oxidation of many biological molecules, in particular unsaturated lipids. ${ }^{106}$ Singlet oxygen can be generated in vitro by exposing to light organic dyes, such as Rose Bengal (excitation at $560 \mathrm{~nm}$ ), or nanoparticles such as $\mathrm{ZnO}$ (excitation at $340 \mathrm{~nm}$ ). ${ }^{107}$ The level of ${ }^{1} \mathrm{O}_{2}$ can be assessed by measuring its reaction with an 
hindered amine (such as 2,2,6,6-tetramethyl-4-piperidone) to yield the corresponding nitroxide, whose presence can be detected by EPR spectroscopy. ${ }^{107,108}$

\subsection{How to avoid pitfalls in antioxidant activity determination of nanomaterials}

When applied to nanoantioxidants, methods based on spectrophotometric or fluorimetric detection suffer from interferences due to the overlap to the absorption bands of the probe or of the reaction products with that of the nanomaterial. Noble metal based nanomaterials display localized plasmon resonance properties at visible wavelengths, which cause strong absorption and/or intense scattering, which depend on the dimension, shape and surface of the nano objects. Moreover, interferences may not be constant during the assay, because of aggregation occurring during the assay. For instance, $\mathrm{SiO}_{2} \mathrm{NPs}$ functionalized with gallic acid undergo extensive agglomeration after reacting with $\mathrm{DPPH} \bullet{ }^{74}$ In the case of the tests based on stable radicals (such as DPPH•), these limitations can be overcome by using EPR detection or by removing the nanomaterial with centrifugation or filtration before the assay. ${ }^{101}$ However, because of the long time needed to separate the unreacted probe from the nanoantioxidant, in the second case only the stoichiometry of the reaction can be determined. Similarly, the suspension of other nanomaterials like $\mathrm{SiO}_{2} \mathrm{NPs}$ or clay materials may give excessive light scattering and EPR spectroscopy could represent a valid alternative to spectrophotometry. Unfortunately, it can hardly be used in the case of ferromagnetic nanomaterials. Overall, the measurement of the oxygen consumption during an inhibited autoxidation by a Clark electrode or by a pressure sensor appears as the most reliable and versatile method, and one of the most appealing as concerns the ease of procedure and analysis, and the relatively low weight of interferences. ${ }^{109}$ Specific enzyme-like activities need to be assessed with specific assays (vide supra) and, ideally, a combination of those assays with inhibited autoxidation studies would compose a comprehensive fully informative picture of the antioxidant potential of a novel nanomaterial.

\section{5) CONCLUSIONS}


This review highlights the progress made in recent years in the field of nanomaterials endowed with antioxidant properties. It provides a classification based on the mechanism of action and on the main chemical methods used to evaluate their activity. These materials can potentially overcome many limitations of small-molecule antioxidants, by exhibiting superior bioavailability, higher stability and the possibility to reach specific targets. However, nanoantioxidants pose also new challenges to the analytical determination of their radical trapping activity, mainly because of the strong absorption and scattering of the samples. Methodologies which don't rely on spectrophotometric methods, in particular oximetry, may be considered as privileged tools to guide research towards increasingly effective materials.

\section{CONFLICTS OF INTEREST}

There are no conflicts of interest to declare.

\section{ACKNOWLEDGEMENTS}

This work was supported by the University of Bologna (FARB Project FFBO123154).

\section{REFERENCES}

1) K. U. Ingold and D. A. Pratt, Chem. Rev., 2014, 114, 9022-9046.

2) J. Cadet and J. R. Wagner, Arch. Biochem. Biophys., 2014, 557, 47-54.

3) H. Zhang and H. J. Forman, Free Radic. Biol. Med., 2017, 111, 219-225.

4) J. Morry, W. Ngamcherdtrakul and W. Yantasee, Redox Biology, 2017, 11, 240-253.

5) Z. A. M. Zielinski and D. A. Pratt, J. Org. Chem., 2017, 82, 2817-2825.

6) M. J. Davies, Biochem. J., 2016, 473, 805-825. 
7) S. Chetyrkin, M. Mathis, V. Pedchenko, O. A. Sanchez, W. H. McDonald, D. L. Hachey, H. Madu,

D. Stec, B. Hudson and P. Voziyan, Biochem., 2011, 50, 6102-6112.

8) R. Amorati and L. Valgimigli, Free Radic. Res., 2015, 49, 633-649.

9) T. G Polefka, T. A Meyer, P. P. Agin and R. J Bianchini, J. Cosmet. Dermatol., 2012, 11, 134143.

10) N. R. Perron and J. L. Brumaghim, Cell. Biochem. Biophys., 2009, 53, 75-100.

11) J. Lu and A. Holmgren, Free Radic. Biol. Med., 2014, 66, 75-87.

12) M. D. Brand, C. Affourtit, T. C. Esteves, K. Green, A. J. Lambert, S. Miwa, J. L. Pakay, and N. Parker, Free Radic. Biol. Med., 2004, 37, 755 - 767.

13) R. Amorati, L. Valgimigli, P. Diner, K. Bakhtiari, M. Saeedi, and L. Engman, Chem. Eur. J., 2013, 19, 7510-7522.

14) L. Bedard, M. J. Young, D. Hall, T. Paul and K. U. Ingold, J. Am. Chem. Soc., 2001, 123, 1243912448.

15) M. C. Krishna, A. Russo, J. B. Mitchell, S. Goldstein, H. Dafni, and A. Samuni, J. Biol. Chem., 1996, 271, 26026-26031.

16) P. Poprac, K. Jomova, M. Simunkova, V. Kollar, C. J. Rhodes, and M. Valko, Trends Pharmacol. Sci., 2017, 38, 592-607.

17) B. Hu, Y. Ting, X. Yang, W. Tang, X. Zeng and Q. Huang, Chem. Commun., 2012, 48, 24212423.

18) Y. Luo and Q. Wang, J. Appl. Polym. Sci., 2014, 131, 40696-40707.

19) C. E. Astete, D. Dolliver, M. Whaley, L. Khachatryan, and C. M. Sabliov, ACS Nano, 2011, 12, 9313-9325. 
20) S. Trombino, R. Cassano, T. Ferrarelli, E. Barone, N. Picci and C. Mancuso, Colloids Surf. B, 2013, 109, 273- 279 .

21) Y. Lvov, W. Wang, L. Zhang and R. Fakhrullin, Adv. Mater., 2016, 28, 1227-1250.

22) L. Gastaldi, E. Ugazio, S. Sapino, P. Iliade, I. Miletto and G. Berlier, Phys. Chem. Chem. Phys., 2012, 14, 11318-11326.

23) J. Li, W. Liu, X. Wu and X. Gao, Biomaterials, 2015, 48, 37-44.

24) W. He, Y.-T. Zhou, W. G. Wamer, X. Huc, X. Wu, Z. Zheng, M. D. Boudreau and J.-J. Yin, Biomaterials, 2013, 34, 765-773.

25) J. Fan, J.-J. Yin, B. Ning, X. Wu, Y. Hu, M. Ferrari, G. J. Anderson, J. Wei, Y. Zhao and G. Nie, Biomaterials, 2011, 32, 1611-1618.

26) Y. Liu, H. Wu, M. Li, J.-J. Yin and Z. Nie, Nanoscale, 2014, 6, 11904-11910.

27) B. C. Nelson, M. E. Johnson, M. L. Walker, K. R. Riley and C. M. Sims, Antioxidants, 2016, 5, 15.

28) J. Mu, L. Zhang, M. Zhao and Y. Wang, J. Mol. Catal. A Chem., 2013, 378, 30-37.

29) T. Pirmohamed, J. M. Dowding, S. Singh, B. Wasserman, E. Heckert, A. S. Karakoti, J. E. S. King, S. Seal and W.T. Self, Chem. Commun., 2010, 46, 2736-2738.

30) N. Singh, M. Azharuddin Savanur, S. Srivastava, P. D’Silva and G. Mugesh, Angew. Chem. Int. Ed., 2017, 56, 14267-14271.

31) Z. Chen, J.-J. Yin, Y.-T. Zhou, Y. Zhang, L. Song, M. Song, S. Hu, and N. Gu, ACS Nano, 2012, 6, 4001-4012. 
32) B. Silvestri, G. Vitiello, G. Luciani, V. Calcagno, A. Costantini, M. Gallo, S. Parisi, S. Paladino, M. Iacomino, G. D’Errico, M. F. Caso, A. Pezzella, and M. d'Ischia, ACS Appl. Mater. Interfaces, $2017,9,37615-37622$.

33) J. Dong, L. Song, J.-J. Yin, W. He, Y. Wu, N. Gu and Y. Zhang, ACS Appl. Mater. Interfaces, 2014, 6, 1959-1970.

34) Y. Nosaka and A. Y. Nosaka, Chem. Rev., 2017, 117, 11302-11336.

35) H. Wei and E. Wang, Chem. Soc. Rev., 2013, 42, 6060-6093.

36) M. S. Wason, J. Colon, S. Das, S. Seal, J. Turkson, J. Zhao and C. H. Baker, Nanomedicine, 2013, 9, 558-569.

37) I. Celardo, J. Z. Pedersen, E. Traversa and L. Ghibelli, Nanoscale, 2011, 3, 1411.

38) J.-D. Cafun, K. O. Kvashnina, E. Casals, V. F. Puntes and P. Glatzel, ACS Nano, 7, 2013, 10726 10732.

39) D. Damatov and J. M. Mayer, Chem. Commun., 2016, 52, 10281- 10284.

40) J. Mu, L. Zhang, M. Zhao and Y. Wang, ACS Appl. Mater. Interfaces, 2014, 6, 7090-7098.

41) A. A. Vernekar, D. Sinha, S. Srivastava, P. U. Paramasivam, P. D’Silva and G. Mugesh, Nat. Commun., 2014, 5, 5301.

42) R. Ragg, M. N. Tahir, and W. Tremel, Eur. J. Inorg. Chem., 2016, 13, 1906-1915.

43) Y. Huang, C. Liu, F. Pu, Z. Liu, J. Ren and X. Qu, Chem. Commun., 2017, 53, 3082-3085.

44) J. Cedrowski, G. Litwinienko, A. Baschieri, and R. Amorati, Chem. Eur. J., 2016, 22, 1644116445.

45) M. Hayyan, M. A. Hashim and I. M. AlNashef, Chem. Rev., 2016, 116, 3029-3085.

46) B. H. J. Bielski and A. O. Allen, J. Phys. Chem., 1977, 81, 1048-1050. 
47) C. Ge, G. Fang, X. Shen, Y. Chong, W. G. Wamer, X. Gao, Z. Chai, C. Chen, and J.-J. Yin, ACS Nano, 2016, 10, 10436-10445.

48) K. Korschelt, R. Ragg, C. S. Metzger, M. Kluenker, M. Oster, B. Barton, M. Panthöfer, D. Strand, U. Kolb, M. Mondeshki, S. Strand, J. Brieger, M. N. Tahir and W. Tremel, Nanoscale, 2017, 9, 39523960.

49) R. Ragg, A. M. Schilmann, K. Korschelt, C. Wieseotte, M. Kluenker, M. Viel, L. Volker, S. Preiß, J. Herzberger, H. Frey, K. Heinze, P. Blumler, M. N. Tahir, F. Natalio and W. Tremel, J. Mater. Chem. B, 2016, 4, 7423-7428.

50) E. L. G. Samuel, D. C. Marcano, V. Berka, B. R. Bitner, G. Wu, A. Pottera, R. H. Fabian, R. G. Pautler, T. A. Kent, A.-L. Tsai and J. M. Tour, Proc. Natl. Acad. Sci. U. S. A., 2015, 112, 2343-2348.

51) I. Fenoglio, M. Tomatis, D. Lison, J. Muller, A. Fonseca, J. B. Nagy and B. Fubini, Free Radic. Biol. Med., 2006, 40, 1227-1233.

52) G.-F. Liu, M. Filipovic, I. Ivanovic-Burmazovic, F. Beuerle, P. Witte and A. Hirsch, Angew. Chem. Int. Ed., 2008, 47, 3991-3994.

53) S. S. Ali, J. I. Hardt, K. L. Quick, J. S. Kim-Han, B. F. Erlanger, T.-T. Huang, C. J. Epstein, and L. L. Dugan, Free Radic. Biol. Med., 2004, 37, 1191-1202.

54) Y. Liu, K. Ai, X. Ji, D. Askhatova, R. Du, L. Lu, and J. Shi, J. Am. Chem. Soc., 2017, 139, $856-862$.

55) Y. Huang, Z. Liu, C. Liu, E. Ju, Y. Zhang, J. Ren and X. Qu, Angew. Chem. Int. Ed., 2016, 55, $6646-6650$.

56) A. Watanabe, M. Kajita, J. Kim, A. Kanayama, K. Takahashi, T. Mashino and Y. Miyamoto, Nanotechnology, 2009, 20, 455105. 
57) S. S. Lee, W. Song, M. Cho, H. L. Puppala, P. Nguyen, H. Zhu, L. Segatori, and V. L. Colvin, ACS Nano, 2013, 7, 9693-9703.

58) S. Balaji, B. Kumar Mandal, S. Ranjan, N. Dasgupta and R. Chidambaram, J. Photochem. Photobiol. B, 2017, 170, 125-133.

59) K.-Y. Ju, Y. Lee, S. Lee, S. B. Park, and J.-K. Lee, Biomacromolecules, 2011, 12, 625-632.

60) R. Amorati, S. Menichetti, C. Viglianisi and M. C. Foti, Chem. Commun., 2012, 48, 1190411906.

61) L. Valgimigli, R. Amorati, S. Petrucci, G. F. Pedulli, D. Hu, J. J. Hanthorn and D. A. Pratt, Angew. Chem. Int. Ed., 2009, 48, $8348-8351$.

62) J. J. Warren, T. A. Tronic and J. M. Mayer, Chem. Rev. 2010, 110, 6961-7001.

63) R. Amorati, A. Baschieri, G. Morroni, R. Gambino and L. Valgimigli, Chem. Eur. J., 2016, 22, $7924-7934$.

64) D. Barana, S. Danish Ali, A. Salanti, M. Orlandi, L. Castellani, T. Hanel, and L. Zoia, ACS Sustainable Chem. Eng., 2016, 4, 5258-5267.

65) D. Tian, J. Hu, J. Bao, R. P. Chandra, J. N. Saddler and C. Lu, Biotechnol Biofuels, 2017 10, $192-$ 202.

66) R. Amorati, G. F. Pedulli, D. A. Pratt and L. Valgimigli, Chem. Commun., 2010, 46, 5139-5141.

67) S. Goldstein, and A. Samuni, J. Phys. Chem. A, 2007, 111, 1066-1072.

68) A. Karakoti, S. Singh, J. M. Dowding, S. Sealac and W. T. Self, Chem. Soc. Rev., 2010, 39, 44224432.

69) J. N. Schrauben, R. Hayoun, C. N. Valdez, M. Braten, L. Fridley and J. M. Mayer, Science, 2012, 336, 1298-1301. 
70) Z. Nie, K. J. Liu, C.-J. Zhong, L.-F. Wang, Y. Yang, Q. Tian and Y. Liu, Free Radic. Biol. Med., 2007, 43, 1243-1254.

71) L. Du, S. Suo, G. Wang, H. Jia, K. J. Liu, B. Zhao, and Y. Liu, Chem. Eur. J., 2013, 19, 1281 1287.

72) R. Ebabe Elle, S. Rahmani, C. Lauret, M. Morena, L. P. R. Bidel, A. Boulahtouf, P. Balaguer, J.P. Cristol, J.-O. Durand, C. Charnay, and Eric Badia, Mol. Pharm., 2016, 13, 2647-2660.

73) G. A. Sotiriou, C. O. Blattmanna and Y. Deligiannakis, Nanoscale, 2016, 8, 796-803.

74) Y. Deligiannakis, G. A. Sotiriou, and S. E. Pratsinis, ACS Appl. Mater. Interfaces, 2012, 4, 6609-6617.

75) C. Viglianisi, V. Di Pilla, S. Menichetti, V. M. Rotello, G. Candiani, C. Malloggi and R. Amorati, Chem. Eur. J., 2014, 20, $6857-6860$.

76) M. Massaro, R. Amorati, G. Cavallaro, S. Guernelli, G. Lazzara, S. Milioto, R. Noto, P. Poma and S. Riela, Colloids Surf. B, 2016, 140, 505-513.

77) M. Massaro, S. Riela, S. Guernelli, F. Parisi, G. Lazzara, A. Baschieri, L. Valgimigli and R. Amorati, J. Mater. Chem. B, 2016, 4, 2229-2241.

78) C. N. McEwen, R. G. McKay and B. S. Larsen, J. Am. Chem. Soc., 1992, 114, 4412-4414.

79) R. M. Lucente-Schultz, V. C. Moore, A. D. Leonard, B. K. Price, D. V. Kosynkin, M. Lu, R. Partha, J. L. Conyers and J. M. Tour, J. Am. Chem. Soc., 2009, 131, 3934-3941.

80) R. F. Enes, A. C. Tomè, J. A. S. Cavaleiro, R. Amorati, M. G. Fumo, G. F. Pedulli and L. Valgimigli, Chem. Eur. J., 2006, 12, 4646 - 4653.

81) R. F. Enes, A. S. F. Farinha, A. C. Tomè, J. A .S. Cavaleiro, R. Amorati, S. Petrucci and G. F. Pedulli, Tetrahedron, 2009, 65, 253-262. 
82) R. Czochara, J. Kusio and G. Litwinienko, RSC Adv., 2017, 7, 44021-44025.

83) M. Pavlovic, P. Rouster and I. Szilagyi, Nanoscale, 2017, 9, 369-379.

84) D. Gil, J. Rodriguez, B. Ward, A. Vertegel, V. Ivanov and V. Reukov, Bioengineering, 2017, 4, 18.

85) R. F. Beers and I. W. Sizer, J. Biol. Chem., 1952, 195, 133-140.

86) R. W. Noble and Q. H. Gibson, J. Biol. Chem., 1970, 245, 2409-2413.

87) E. W. Miller, A. E. Albers, A. Pralle, E. Y. Isacoff and C. J. Chang, J. Am. Chem. Soc., 2005, 127, 16652-16659.

88) M. Hermes-Lima, W. G. Willmore, and K. B. Storey, Free Radic. Biol. Med., 1995, 19, 271 280.

89) Y. Li and H. E. Schelhorn, J. Biomol. Tech., 2007, 18, 185 - 187.

90) B. Zhao, F. A. Summers and R. P. Mason, Free Radic. Biol. Med., 2012, 53, 1080-1087.

91) D. Andina, J.-C. Leroux and P. Luciani, Chem. Eur. J., 2017, 23, 13549 - 13573.

92) T. Iwase, A. Tajima, S. Sugimoto, K. Okuda, I. Hironaka, Y. Kamata, K. Takada and Y. Mizunoe, Sci. Rep., 2013, 3, 3081 .

93) M. Lucarini, P. Pedrielli, G. F. Pedulli, L. Valgimigli, D. Gigmes, and P. Tordo, J. Am. Chem. Soc., 1999, 121, 11546-11553.

94) S. Kumar, L. Engman, L. Valgimigli, R. Amorati, M. G. Fumo and G. F. Pedulli, J. Org. Chem., 2007, 72, 6046-6055.

95) E. E. Kelley, N. K. H. Khoo, N. J. Hundley, U. Z. Malik, B. A. Freeman and M. M. Tarpey, Free Radic. Biol. Med., 2010, 48, 493-498.

96) A. Z. Haghighi and R. Wei, Anal. Lett., 1998, 31, 981-990. 
97) H. Ukeda, D. Kawana, S. Maeda and M. Sawamura, Biosci. Biotechnol. Biochem., 1999, 63, 485488.

98) H. J. Forman and I. Fridovich, Arch. Biochem. Biophys., 1973, 158, 396-400.

99) P.L. Vandewalle and N.O. Petersen, FEBS Lett., 1987, 210, 195-198.

100) H. Zhao, J. Joseph, H. Zhang, H. Karoui and B. Kalyanaraman, Free Radic. Biol. Med., 2001, 31, 599-606.

101) J. Tournebize, A. Sapin-Minet, G. Bartosz, P. Leroy and A. Boudier, Talanta, 2013, 116, 753763.

102) P. Ionita, Chem. Pap., 2005, 59, 11 - 16.

103) A. Brizzolari, G. M. Campisi, E. Santaniello, N. Razzaghi-Asl, L. Saso and M. C. Foti, Biophys. Chem., 2017, 220, 1-6.

104) Y. Xue, Q. Luan, D. Yang, X. Yao and K. Zhou, J. Phys. Chem. C, 2011, 115, 4433-4438.

105) T. Hamasaki, T. Kashiwagi, T. Imada, N. Nakamichi, S. Aramaki, K. Toh, S. Morisawa, H. Shimakoshi, Y. Hisaeda, and S. Shirahata, Langmuir, 2008, 24, 7354-7364.

106) Y. Akazawa-Ogawa, M. Shichiri, K. Nishio, Y. Yoshida, E. Niki and Y. Hagihara, Free Radical Biol. Med., 2015, 79, 164-175.

107) T. Wen, W. He, Y. Chong, Y. Liu, J.-J. Yin and X. Wu, Phys. Chem. Chem. Phys., 2015, 17, 24937-24943.

108) J.-J, Yin, F. Lao, P. P. Fu, W.G. Wamer, Y. Zhao, P. C. Wang, Y. Qiu, B. Sun, G. Xing, J. Dong, X.-J. Liang and C. Chen, Biomaterials, 2009, 30, 611-621.

109) R. Amorati, O. A. Attanasi, G. Favi, S. Menichetti, G. F. Pedulli and C. Viglianisi, Org. Biomol. Chem., 2011, 9, 1352-1355. 